JOÃO LUIS RIBEIRO REINO

\title{
A GLOBALIZAÇÃO CULTURAL E OS ESTADOS UNIDOS: O PODER DA INTERNET COMO AGENTE PROPAGADOR DE CULTURA
}

Trabalho de Conclusão do Curso de Relações Internacionais para a Universidade de Brasília, apresentado como requisito parcial à obtenção do título de Especialista em Relações Internacionais

Orientador:

Prof. Virgílio Caixeta Arraes 


\section{JOÃO LUIS RIBEIRO REINO}

\section{A GLOBALIZAÇÃO CULTURAL E OS ESTADOS UNIDOS: O PODER DA INTERNET COMO AGENTE PROPAGADOR DE CULTURA}

Trabalho de Conclusão do Curso de Relações Internacionais para a Universidade de Brasília, apresentado como requisito parcial à obtenção do título de Especialista em Relações Internacionais

Orientador:

Prof. Virgílio Caixeta Arraes 
Este trabalho é dedicado à minha mulher, Maíra, e aos meus filhos, Nina e Gabriel. 


\section{AGRADECIMENTOS}

Agradeço a minha família pela paciência e apoio durante todo o período de desenvolvimento desta monografia.

Agradeço em especial ao meu orientador, Professor Virgílio Arraes, pelas aulas inspiradoras e por me aceitar como mais um orientando apesar de todas as suas tarefas. Gostaria de agradecê-lo também por estar sempre disponível para as nossas produtivas reuniões e por me indicar a excelente bibliografia que viabilizou este trabalho, abriu meus olhos para questões importantes do mundo em que vivemos e me motivou a continuar minha carreira acadêmica em direção a novas conquistas.

Agradeço também ao Professor Eiti Sato pelas minhas primeiras reuniões de tutoria e orientação. Suas reuniões me ajudaram a definir o tema de pesquisa e me tiraram do caminho tentador da "teoria da conspiração".

Agradeço aos funcionários da Biblioteca Nacional de Brasília por propiciarem um excelente ambiente para o estudo e a concentração. E aos funcionários da Biblioteca Central da Universidade de Brasília pela prestatividade e profissionalismo.

Agradeço a vida por ela existir. 


\section{RESUMO}

Baseando-se em um dos pilares do conceito tríptico de poder definido por E. H. Carr, o estudo da globalização cultural a partir da análise dos fluxos internacionais de informação é uma forma de verificar o poder dos atores do sistema internacional. O advento da Internet elevou a velocidade e a intensidade da distribuição de conteúdo cultural a patamares jamais alcançados pela humanidade. Os Estados Unidos, donos de longo histórico no exercício da influência cultural pelos meios de comunicação, continuam exercendo seu poder na Internet. O poder cultural americano é exercido principalmente por grandes corporações de mídia, responsáveis pela produção e distribuição de produtos culturais pela Internet através de uma sofisticada e próspera indústria cultural. O grau de internacionalização dos principais sites americanos de notícias comprova a alta visibilidade do material publicado pelas corporações de mídia americanas. Não obstante, a força cultural homogeneizadora americana convive com forças diversificadoras que, apesar de existirem, não tem impacto relevante nos grandes fluxos internacionais de informação. 


\begin{abstract}
Based on one of the pillars of E. H. Carr's concept of power, the study of cultural globalization by analysis of the international flows of information is one way to verify the power of actors in the international system. The advent of the Internet has increased the velocity and intensity of cultural content distribution to levels never before reached by mankind. The United States have a long history on the exercise of cultural influence through different means of communication, and still exercise their power through the Internet. American cultural power is exercised mainly by large media corporations in charge of the production and distribution of cultural products on the Internet through a sophisticated and prosperous cultural industry. The level of internationalization of the main American news websites substantiates the high visibility of the material published by American media corporations. Nonetheless, the American homogenizing cultural force co-exists with diversifying forces which, although do exist, do not have any relevant impact on the major international flows of information.
\end{abstract}




\section{LISTA DE GRÁFICOS}

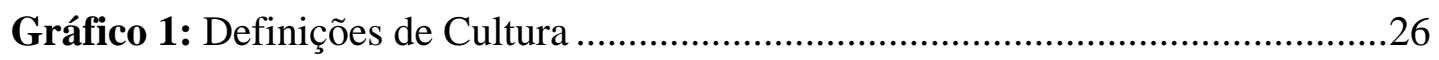

Gráfico 2: Utilização Internacional de Largura de Banda ......................................41

Gráfico 3: Largura de Banda Disponível Interregionalmente..................................42

Gráfico 4: Visitas Estrangeiras aos Principais Sites de Notícias ..............................50

Gráfico 5: Visitas Estrangeiras aos Sites das Principais Revistas.............................52

Gráfico 6: PIB dos Três Países ..........................................................................53

Gráfico 7: PIB dos Três Países Mais a China ...........................................................54

Gráfico 8: IDH dos Três Países mais a China.........................................................55 


\section{LISTA DE TABELAS}

Tabela 1: Número de visitas aos principais sites de notícias dos três países ............26

Tabela 2: Porcentual de visitas locais aos sites analisados ......................................41

Tabela 3: Número de visitas e porcentual de visitas locais aos sites das principais

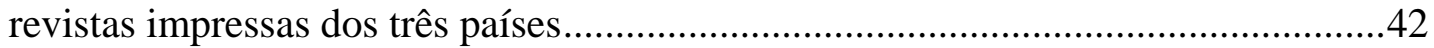




\section{LISTA DE TABELAS}

\section{LISTA DE GRÁFICOS}

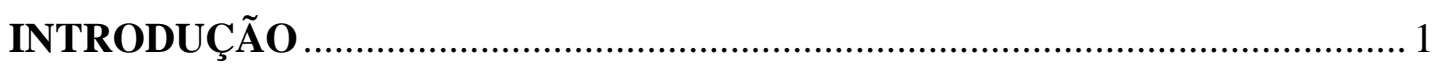

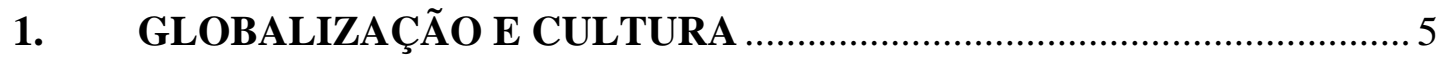

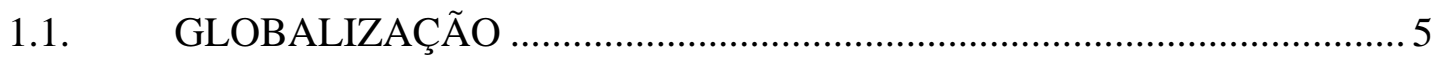

1.2. CULTURA E AS RELAÇÕES INTERNACIONAIS .............................. 12

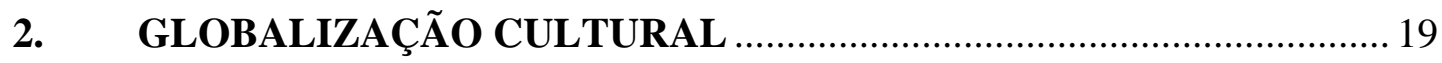

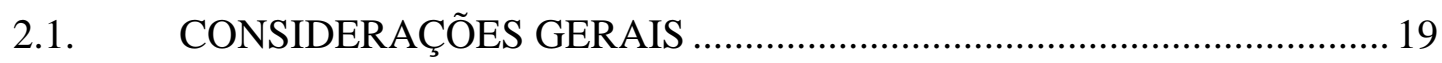

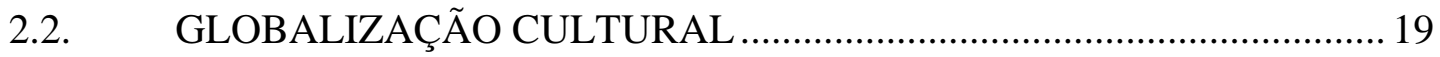

2.3. A GLOBALIZAÇÃO CULTURAL CONTEMPORÂNEA E OS

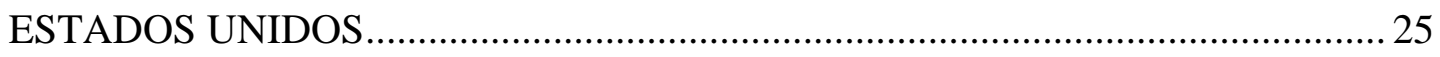

3. A INTERNET E A GLOBALIZAÇÃO CULTURAL ............................. 30

3.1. CONSIDERAÇÕES GERAIS .............................................................. 30

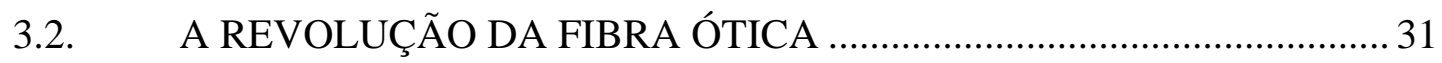

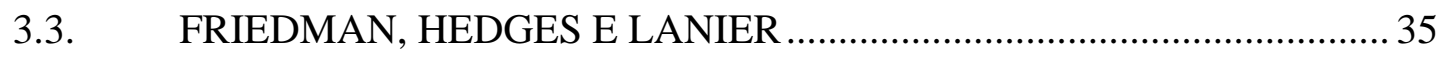

3.4. A INTERNET E A INFLUÊNCIA CULTURAL AMERICANA ............. 39

3.5. IMPERIALISMO OU SICRONIZAÇÃO CULTURAL? ........................... 50

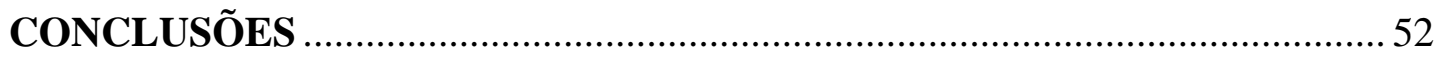

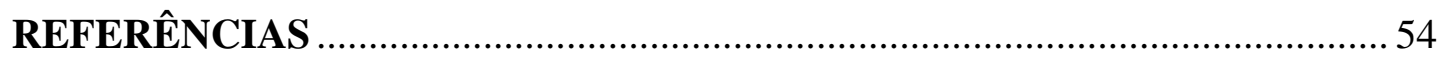

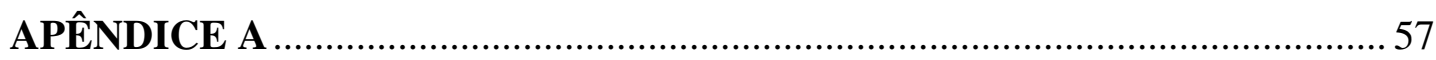




\section{INTRODUÇÃO} In a broad sense, the study of the international flow of information is
another approach to the study of international relations.

- Hamid Mowlana*

\section{Apresentação}

As Relações Internacionais são uma área de estudo que se beneficia de contribuições vindas de diversos outros campos.

Ao iniciar a XI Especialização em Relações Internacionais da Universidade de Brasília, o autor do presente trabalho contemplou a possibilidade de unir, na elaboração de sua monografia de conclusão de curso, conhecimentos novos adquiridos na pós-graduação àqueles adquiridos em seu curso de graduação: Redes de Computadores.

A união destas duas áreas levou o pesquisador à questão da globalização cultural e da Internet como agente da mesma.

Apesar de conjuntural, o material disponível sobre o assunto é amplo. Por esta razão o trabalho limitou-se às fontes consideradas mais importantes e relevantes, como David Held, Jongsuk Chay, Chris Hedges, Thomas Friedman, Noam Chomsky, entre outros.

Dada as características do presente trabalho, analisar-se-ão de forma sintética os itens: cultura, globalização, globalização da cultura, a influência cultural americana, a Internet e o tráfego de grandes sites de notícias.

O pesquisador espera poder prosseguir a sua análise sobre o tema nas esferas subseqüentes da pós-graduação, ou seja, mestrado e possivelmente doutorado.

* 1990, p. 226 
Tema

Nas últimas décadas, as telecomunicações evoluíram em ritmo acelerado. Os meios tradicionais se expandiram e novos meios foram criados. Entre eles, destacase a Internet.

Estando os meios de comunicação a serviço da sociedade, as informações que circulam por eles não são neutras. Elas expressam determinadas visões de mundo, de diferentes grupos do sistema internacional.

Ante o exposto, propõe-se estudar a presença americana na Internet e o seu impacto na globalização cultural.

\section{Justificativa}

A circulação da informação expressa diferentes formas de poder ao agregar idéias, opiniões, comportamento e cultura.

A Internet como meio de circulação da informação tem se tornado cada vez mais relevante no sistema internacional. A recente crise entre a empresa Google e o governo da China é um exemplo do poder de influência que o conteúdo que transita na rede pode exercer sobre a sociedade e os Estados.

Tendo isso em vista, a presente monografia se debruçará sobre a globalização cultural ao encaixá-la como um dos três componentes do poder político conforme definição clássica de E. H. Carr (2001).

De acordo com a concepção clássica de Carr (2001, p. 143-188), o poder nas relações internacionais se dividiria em poder militar, poder econômico e poder sobre a opinião.

Neste sentido, optou-se por analisar dentro do tema do poder sobre a opinião o papel da Internet na produção e distribuição de informação e a influência dos Estados Unidos neste contexto. 


\section{Objetivo Geral}

Definir e analisar a globalização cultural, verificando a participação dos Estados Unidos e seu histórico de influência cultural mundial.

\section{Objetivos Específicos}

Identificar argumentação favorável à idéia da Internet como agente diversificador da cultura;

Identificar argumentação favorável à idéia da Internet como agente homogeneizador da cultura;

Analisar informações de tráfego dos principais sites de notícias do Brasil, dos Estados Unidos e da França a fim de verificar a quantidade de fluxo sobre três idiomas (português, inglês e francês).

\section{Modelo Analítico}

a. Em análise preliminar, o poder real de disseminação cultural pela Internet permanece nas mãos de grandes corporações produtoras e distribuidoras de informação e conteúdo cultural;

b. A variável dependente do presente estudo é a Internet e seu poder de disseminação de cultura, o qual pode ser diversificador (nas mãos de muitas agentes) ou homogeneizador (nas mãos de uma ou poucos agentes), de acordo com as variáveis independentes. As variáveis independentes são as forças que influenciam (ou tem o potencial de fazê-lo) a disseminação de cultura pela Internet; são elas: as corporações (na forma de produtoras e distribuidoras de conteúdo cultural e na forma de anunciantes), os Estados, os cidadãos comuns e os sites agregadores de conteúdo. As presentes variáveis não esgotam o rol de forças atuantes na rede, mas são as principais variáveis independentes sobre as quais o estudo se debruça.

c. O reflexo de uma variável do conceito tríptico de poder (militar, econômico e cultural) dentro do sistema internacional, compreendido no trabalho como a interação constante de diversos atores por diferentes formas de fluxo. 


\section{Metodologia}

Para a definição de globalização, o presente trabalho será guiado pelo marco orientador traçado por Prado (2006), no qual são definidas quatro linhas de interpretação do fenômeno. As quatro linhas são apresentadas e discutidas na primeira parte do primeiro capítulo.

Na definição de cultura, utiliza-se a abordagem de R.B.J. Walker (1990, p. 317), complementada, principalmente, por Held (1999) e Elliot (1949).

Para a análise da globalização cultural, utiliza-se a metodologia empregada por Held (1999), que trata a globalização cultural em um argumento de cinco partes. Quatro das quais são apresentadas e discutidas sob a perspectiva dos autores pesquisados.

Para a análise do fluxo de informações na Internet primeiramente foram identificados os principais sites de notícias e revistas dos Estados Unidos, Brasil e França ${ }^{1}$. Logo em seguida foram coletados dados sobre o tráfego e porcentual de visitas locais aos sites.

Algumas tabelas e gráficos foram elaborados com base nos dados coletados e, de acordo com essas informações, identificados os achados em relação ao tema do estudo.

O marco temporal é a conjuntura. O período que marca a ascensão da Internet a partir dos anos 90 até os dias de hoje.

\footnotetext{
${ }^{1}$ Dados referentes a sites chineses foram acrescentados ao final da análise apenas por questões ilustrativas.
} 


\section{GLOBALIZAÇÃO E CULTURA}

Os que avaliam a globalização simplesmente com base em estatísticas comerciais - ou como um fenômeno puramente econômico, em vez de enxergá-lo como algo que afeta tudo, da aquisição de poder à cultura e ao funcionamento das instituições hierárquicas - não percebem o impacto dessa mudança.

- Thomas L. Friedman*

\subsection{GLOBALIZAÇÃO}

O termo globalizado tem sido frequentemente empregado para descrever diversos aspectos do período pelo qual o mundo atravessa. Entretanto, apesar do seu uso amplo, não há consenso entre os especialistas sobre o que de fato é a globalização.

Trata-se de um período histórico? A integração financeira mundial? Um fenômeno social impulsionado pela tecnologia? A literatura aponta para todas as alternativas acima. E apesar da inexistência de uma definição única, o termo é "um belo exemplo de um conceito que embora impreciso, cumpre seu papel de legitimar uma interpretação do mundo” (PRADO, 2006).

Normalmente apresentada apenas pelas suas conseqüências, a globalização é muito mais do que seus resultados. Ela é real, ampla e indissociável da conjuntura humana atual. O termo trás em si uma tônica “fatalista” (PRADO, 2006), incentivada pela mídia de massa, e que incita reações calorosas por parte daqueles que são contra ou a favor do processo.

Vulgarmente, seus opositores acreditam que ela resultará na destruição do meio-ambiente, no aumento desenfreado da desigualdade mundial e na vitória do consumismo superficial. Enfim, em ruína para a população humana.

Sobre bases não mais concretas, alguns de seus defensores mais vocais a veem como a solução de todos os nossos problemas, que resultará na emergência de

* 2009, p.10 
uma sociedade internacional de povos unidos pela tecnologia e pelo compartilhamento de valores em comum (FRIEDMAN, 2009).

De um ponto de vista menos ideologizado, a globalização tem seus aspectos negativos e positivos. Existem, de fato, bons analistas, com excelentes argumentos apontando os benefícios e as mazelas que o processo tem trazido à humanidade. Mas antes de tudo, a única certeza sobre ela é a sua inevitabilidade. Ela não foi prevista, nem seu futuro será, mas ela existe e não pode ser parada.

Talvez, à medida que as forças impulsionadoras do processo forem sendo identificadas com mais precisão, a globalização possa ser desacelerada ou estimulada, mas dificilmente interrompida.

Nos próximos parágrafos serão apresentadas uma breve introdução histórica do processo e quatro linhas básicas de interpretação, identificadas por Luiz Carlos Prado (2006), e dentro das quais causa e conseqüência estão conectadas como que em um loop onde uma alimenta a outra e juntas dão continuidade ao processo.

Historicamente, o termo globalização, começou a ser empregado nos anos 80, substituindo conceitos como internacionalização e transnacionalização (PRADO, 2006). Nessa perspectiva, o termo representa uma idéia cujo objetivo é fazer uma separação entre o sistema internacional (antigo) e o global (novo).

Segundo Arraes², no sistema global os Estados não são mais os principais atores, particularmente os Estados periféricos, que na contemporaneidade perdem a capacidade de atuar de acordo com os moldes tradicionais e são obrigados a dividir o pódio com atores não-estatais, como as corporações multinacionais e as organizações internacionais.

O papel do Estado também se desloca de tomador de decisão e interventor para regulador.

\footnotetext{
${ }^{2}$ ARRAES, V. XI Especialização em Relações Internacionais, UnB. Aula do dia 21/09/2009
} 
Outra mudança de grande importância observada na globalização, e que será bastante útil no decorrer desse trabalho, é o deslocamento da natureza do próprio indivíduo que, não mais um simples cidadão, adquire o status de consumidor.

Mas ao invés de se deter às origens do termo em si, esta seção se foca na origem do próprio processo. Neste ponto, existe certo consenso na literatura de que a globalização, ou a sua mais recente expansão, começou depois da queda do muro de Berlim em 1989 (FRIEDMAN, 2009 p. 66-75; PRADO, 2006; RAMONET 1998 p. 55-56 apud PRADO, 2006). A revolução popular, silenciosa e pacífica, que veio de dentro da Alemanha e resultou na queda do muro, incentivaria uma série de outras nações a assumirem as rédeas de seu futuro.

Além disso, a distensão das relações entre os Estados Unidos e a ex-União Soviética, através de acordos de controle de armamentos e détente ${ }^{3}$ contribuiu para o fortalecimento dos movimentos de direitos civis na URSS e nos países do leste europeu, que a partir de então adquiriram “espaço de manobra” suficiente para destronarem os governos autoritários da região (CZEMPIEL, 2000, p. 347-349).

Segundo Czempiel, as reformas introduzidas por Gorbachev em 1985, a Perestroika e a Glasnost, tinham como objetivo revigorar o comunismo, mas acabaram por enfraquecê-lo devido à conseqüente, e imprevisível, redução das tensões internacionais (2000, p. 348).

Teoricamente, Czempiel aponta a lei de Seeley como uma das explicações desses acontecimentos (2000, p. 348). De acordo com a lei, “o grau de liberdade dentro de um país é o inverso do grau de pressão externa contra suas fronteiras.”4

\footnotetext{
${ }^{3}$ A fase de distensão da Guerra Fria iniciou-se logo após a Crise dos Mísseis, em 1962, especialmente após a assinatura do Tratado de Moscou (1963), onde ambos os países se comprometiam a não invadir a Antártida, e a assinatura do Tratado de Não-Proliferação Nuclear (1968), onde os signatários, incluindo outros países além dos EUA e da URSS, se comprometiam a não difundir tecnologia nuclear e a reduzirem seus próprios armamentos. Apesar de ter havido uma segunda fase de tensionamento durante o governo Reagan, nos EUA, as pressões internas fizeram com que o presidente Reagan se voltasse, mais uma vez, às questões de controle de armamento quando Gorbachev subiu ao poder em 1985.

${ }^{4}$ Citado em Otto Hintze, Staat und Verfassung. Gesammelte Abhandlugen zur Allgemeine Verfassugsgeschichte, Ed. G. Oestreich (Göttingen, Vandenhoeck und Ruprecht, 1962, p. 411), apud Czempiel, 2000, p. 348
} 
Com efeito, a partir do momento que a pressão vinda de fora da URSS e dos outros centros comunistas, como a Alemanha Oriental, cedeu, ou seja, quando o risco iminente de uma guerra nuclear mundial já não era mais tão presente, não foi mais possível manter o autoritarismo dentro de suas fronteiras.

Além disso, as idéias de prosperidade ocidental já haviam alcançado o leste, e seus partidários no mundo comunista estavam apenas esperando o momento oportuno para manifestarem suas demandas.

Tendo o período acima como ponto de partida da globalização é possível observar que ela está ligada a diferentes aspectos da existência humana. Ela representa uma época, representa mudanças políticas, mudanças econômicas, e até mudanças comportamentais, e está intimamente associada a valores ocidentais.

Prado (2006) identificou quatro “linhas básicas de interpretação” da globalização. Segundo ele a globalização pode ser interpretada como:

i) Uma época histórica;

ii) Um fenômeno sociológico de compressão do espaço e tempo;

iii) A hegemonia dos valores liberais;

iv) Um fenômeno sócio-econômico.

\subsubsection{Uma época histórica}

A época histórica é aquela supracitada, que iniciou-se com a queda do muro de Berlim (1989) e o desaparecimento da União Soviética (1991) e vai até os dias de hoje.

\subsubsection{Um Fenômeno Sociológico de Compressão do Espaço e Tempo}

A compressão de espaço e tempo é um fenômeno observado por diversos autores (FRIEDMAN, 2009; GIDDENS, 1990 apud MORRIS, 1997; HELD, 1999, p. 330; SMITH, 1995, apud MORRIS, 1997). Pode-se dizer que o fenômeno de compressão do espaço e tempo tornou-se mais perceptível a partir de 1837, após a invenção do telégrafo por Samuel Morse e a sua difusão. 
A partir desse momento, pequenas comunicações, que precisavam cruzar longas distâncias e demoravam horas, dias e até meses para atingir seu destinatário, passaram a ser realizadas em questões de segundos.

Não se deve subestimar o aspecto revolucionário que o telégrafo teve para as comunicações da época e não é exagero supor que esse mesmo nível de revolução comunicacional só tenha sido novamente vivenciado pela humanidade mais de cem anos depois, em 1991, com o advento da Internet e a abertura da World Wide Web.

Mas não foram apenas os avanços nas telecomunicações que encurtaram as distâncias. Os avanços nos meios de transporte também foram uma importante força globalizadora. (HELD, 1999, p. 329; ROSENAU, 2003, p. 15).

A começar pelo transporte a vapor, e finalmente pelos motores a jato, a tecnologia de transporte permitiu o aumento no fluxo de bens, que favoreceu e barateou o comércio internacional, mas, mais importante ainda, promoveu a circulação de pessoas. Pessoas e toda a sua bagagem intelectual, cultural e moral.

O aumento no fluxo de forasteiros vindo de regiões cada vez mais distantes permitiu uma interação cultural entre os povos sem precedentes. A sensação de compressão do espaço se manifestava cada vez mais.

\subsubsection{A Hegemonia dos Valores Liberais}

No que tange os valores liberais, alguns autores consideram a globalização como a democratização das nações e a disseminação dos valores liberais, um caminho sem volta e para o qual todos os países caminham (FUKUYAMA, 1992 apud PRADO, 2006). Em outras palavras, a “inevitável” americanização do mundo.

Houve, de fato, ao longo da história, ondas de democratização. A última, a chamada terceira onda (HUNGTINTON, 1991 apud PRADO, 2006), ocorreu da década de 1970 até a década de 1990, com a democratização de países no sul da Europa e na América Latina, e elevou o número de países sob regimes democráticos para mais de cem. 
Entretanto, o conceito de democracia ainda é um conceito em formação. Alguns autores identificaram critérios para distinguir um governo democrático de outros tipos de governos (SCHUMPETER, 1961). Porém ainda há divergências sobre o que exatamente faz de um Estado uma democracia.

Ao mesmo tempo, existem diferentes vertentes democráticas. Trata-se da democracia liberal plena? Ou simples democracia eleitoral representativa? O Brasil caminha em direção à democracia participativa, enquanto isso, segundo o Professor Dr. Krystian Complak*, na Europa a democracia participativa não é uma opção, pois considera-se que o cidadão médio não está preparado para participar diretamente do processo democrático, mas apenas indiretamente, através da tradicional democracia representativa, prevalente no continente europeu.

Além disso, alguns países que ainda governam com mão-de-ferro tem tido forte participação no cenário mundial, tanto político quanto economicamente, e não demonstram intenção de mudarem seus regimes, em particular a China.

Outros Estados veem suas populações aceitarem pelo voto direto democracias que mais parecem antigas ditaduras, como a Venezuela e a Bolívia.

Ou seja, pode ser que estejamos testemunhando não necessariamente o triunfo, mas talvez a emergência de um novo regime, algo entre o autoritarismo tradicional e o que conhecemos como democracia hoje.

\subsubsection{Um Fenômeno Sócio-Econômico}

A globalização como fenômeno sócio-econômico talvez seja a interpretação mais discutida, por se tratar de questões econômicas envolvendo o comércio e as finanças internacionais e por estar diretamente ligado ao bem-estar social dos Estados.

\footnotetext{
* Professor da Universidade de Wroclaw, Polônia, em conferência magna intitulada "A Dignidade do Homem e o Bem Comum, como fundamentos da Democracia” do I Fórum Internacional de Ouvidorias Públicas, em Brasília-DF, dia 10/11/2009.
} 
Sob essa perspectiva, os países pobres se preocupam em empobrecerem ainda mais como resultado do processo de globalização. Ao mesmo tempo em que as nações industrializadas se preocupam em manter, ou expandir, seu poder econômico durante o processo.

Reinaldo Gonçalves (apud PRADO, 2006) cita os três processos que tem ocorrido nos últimos vinte anos que mais afetam as relações econômicas internacionais: a expansão extraordinária dos fluxos internacionais de bens, serviços e capitais; o acirramento da concorrência nos mercados internacionais; e a maior integração entre os sistemas econômicos nacionais.

Tais processos criaram uma arena econômica internacional altamente integrada, mas também eminentemente competitiva e comercialmente agressiva. As empresas que não se adaptarem aos patamares mundiais de competitividade serão, e já estão sendo, simplesmente engolfadas pelo sistema, o que levanta não apenas questões comerciais mas também questões morais e éticas sobre emprego, geração de renda, autonomia, soberania etc.

A quarta linha de interpretação de Prado (2006) se tornou o calcanhar de Aquiles dos partidários da globalização. Seus opositores argumentam que a globalização nada mais é que a expansão de um sistema econômico destrutivo, o mesmo sistema que tem impedido o desenvolvimento industrial de novos países e mantido, há séculos, um pequeno grupo de Estados em posição privilegiada perante o restante do sistema internacional. Também argumentam que ela só irá gerar mais pobreza e aumentar a riqueza daqueles que já a detém.

Já os partidários da globalização defendem que ela tem gerado, e vai continuar gerando, inúmeras oportunidades para a emancipação dos menos privilegiados. Também argumentam que as possibilidades de se alcançar o bemestar econômico são enormes, e sem precedentes, em particular quando se leva em consideração os avanços tecnológicos. 
Friedman garante que "levada a cabo de maneira correta e sustentável, a globalização possui enorme potencial para tirar um grande número de pessoas da pobreza.” (2009, p. 392)

Positiva ou negativa, a globalização é real e inevitável. Alguns a observam e aguardam seus desdobramentos cheios de expectativas e esperança. Outros a repudiam, a consideram artificial e gostariam de vê-la desaparecer.

As quatro linhas de interpretação identificadas por Prado (2006) fornecem um excelente marco orientador para a análise e discussão do processo. Cada uma delas levanta perguntas específicas que podem ser exaustivamente discutidas. Entretanto, o presente estudo abordará uma quinta linha de interpretação, que está relacionada a todas as outras. Trata-se da globalização em seu aspecto cultural.

\subsection{CULTURA E AS RELAÇÕES INTERNACIONAIS}

Segundo Jongsuk Chay (1990), a dimensão cultural das relações internacionais tem sido um dos tópicos mais negligenciados na área. Chay argumenta que a amplitude dos seus limites faz com que o tema seja visto como território incerto muito amplo, onde a energia do teórico pode ser facilmente desperdiçada.

O conceito de cultura é impreciso e repleto de ambigüidades e, como coloca R. B. J. Waker (1990, p. 7), aqueles que gostam de conceitos bem definidos e operacionais podem achar o termo vago e tendencioso.

Com efeito, desde a sua institucionalização como disciplina, o estudo das relações internacionais tem dado maior foco às questões positivistas, orientadas a formulação de políticas, deixando as questões culturais às margens da academia (WALKER, 1990, p. 8).

Não obstante, o fim do século XX e o início do XXI trouxeram acontecimentos que resultaram em mudanças estruturais nas interações entre os atores globais. 
O fim da Guerra Fria, o advento da Internet e os ataques terroristas contra os Estados Unidos em onze de setembro de 2001 chamaram rapidamente a atenção da comunidade internacional para os aspectos culturais que permeiam as interações internacionais.

Entretanto, ao contrário do termo "globalização", o conceito de cultura é tão antigo quanto a humanidade. É um conceito polimorfo que, ao longo da história, mostrou suas diversas facetas nos discursos acadêmicos, políticos, religiosos, artísticos, etc.

Walker sugere que para utilizar o termo no mundo contemporâneo é necessário “desenvolver uma amnésia consciente em relação às suposições e contradições pelas quais o termo foi moldado historicamente” (1990, p. 12, tradução nossa).

Os diferentes significados atribuídos à cultura podem eventualmente ser incompatíveis entre si. Não obstante, assim como o termo "globalização", é a amplitude de alcance do conceito que o fortalece. Trata-se de conceitos amplos e imprecisos, mas que desempenham bem o seu papel.

Raymond Williams (apud WALKER, 1990, p. 4, tradução nossa) dizia que cultura é uma das “duas ou três palavras mais complicadas da língua inglesa”, entretanto alguns autores foram bem sucedidos na transposição do termo para expressões que, apesar de amplas como o próprio conceito, desempenham funções importantes no seu entendimento.

Expressões como os “elementos intangíveis" de Friedman (1990), ou as “forças profundas” de Renouvin, são tentativas interessantes e de certa forma bem sucedidas de forjar expressões que abarquem diversos aspectos culturais de uma sociedade.

Esses elementos ou forças são idéias, comportamentos e processos comuns a grupo. Suas manifestações influenciam as pessoas, os ambientes e os governos. 
Entra-se então no aspecto de exclusividade que o termo “cultura” trás em si. Trata-se daquilo que diferencia o Eu do Outro ${ }^{5}$. Ou seja, os elementos intangíveis não são os mesmos para todos. Eles são os mesmos para um grupo de pessoas.

Com efeito, eles são a força de coesão de um grupo específico dentro de um limite mais ou menos bem estabelecido. No presente estudo, o limite estabelecido é o Estado e o arcabouço cultural comum aos seus cidadãos.

A partir do momento que estudamos um grupo como o Eu, e sua influência sobre (ou oriunda de) o Outro, cultura se transforma em culturas e observamos o surgimento da diversidade como nós conhecemos.

A diversidade é a particularidade, e pode ser lidada com aceitação, ou simplesmente tolerância, para se transformar na "celebração das tradições”, mas também pode encontrar animosidade, contestação ou indiferença, gerando a fragmentação ${ }^{6}$.

Segundo Walker (1990, p. 6), Herder identificou que o clamor pela celebração das tradições vem de comunidades que se levantam contra o clamor da universalização da humanidade, que por sua vez emerge de comunidades particulares, porém dominantes.

Nas relações internacionais, a diferença entre o Eu e o Outro é uma das fontes de conflito. Alimenta nacionalismos e "a aparentemente inevitável tendência para o fracasso da cooperação perante a competição e rivalidade inter-estatal” (WALKER, 1990, p. 4).

\footnotetext{
${ }^{5}$ Sobre esse assunto, Walker (1990, p. 6) esclarece em nota: "As should be clear from the argument below, this theme of the 'politics of otherness', of the constitution of 'difference' by negation of the identity of 'the same' and the variety of struggles to refuse the categories through which mutually exclusive conceptions of self and other, friend and enemy, are legitimized, provides the crucial connection between the analysis of culture in general social and political theory and the historically specific way in which culture has been analysed in the theory of international relations."

${ }^{6}$ De acordo com Walker, esse tema é complexo e diz respeito às alegações de universalismo e pluralismo articuladas por Herder no século XVIII. O tema é mais explorado em "World Politics and Western Reason: Universalism, Pluralism, Hegemony”, em R.B.J. Walker, Ed. Culture, Ideology, and World Order (Boulder: Westview Press, 1984), pp. $182-216$.
} 
Segundo Walker (1990, p. 9), cultura remete a valores, e valores remetem ao Estado, o portador último dos valores de uma sociedade. Entretanto, os Estados vivem em um ambiente hostil, anárquico, onde a aplicação desses mesmos valores, diante da diversidade inter-estatal, não é apenas uma questão moral mas uma questão de segurança.

Os valores não são apenas deixados de fora do “domínio amoral da realpolitik", mas considerados “obstáculos às responsabilidades especiais de estadistas em seus esforços para manter a ordem em um domínio tragicamente desprovido de padrões éticos” (WALKER, 1990, p.10, tradução nossa).

Tendo isso em vista, é possível então concluir que cultura e relações internacionais são forças opostas? Que o fortalecimento de uma requer o enfraquecimento da outra?

Aparentemente sim. Mas uma análise mais cautelosa mostra ao pesquisador que o estudo da cultura também faz parte do arcabouço de responsabilidades do homem de Estado moderno.

A conexão entre cultura e as relações internacionais sempre existiu, mas vem se tornando cada vez mais evidente, em particular a partir da Segunda Guerra Mundial. Thomas S. Eliot escreveu logo após o fim da Segunda Guerra que “estamos cada vez mais conscientes da extensão em que o difícil problema de 'cultura' sublinha os problemas da relação de cada uma das partes do mundo com cada uma das outras” (1949, p.25, tradução nossa).

Para Eliot, cultura está intimamente conectado a religião. O desenvolvimento cultural e religioso de uma sociedade não pode ser separado. O autor vai além e se pergunta se qualquer cultura poderia surgir ou se manter viva sem uma base religiosa. "Podemos [...] perguntar se aquilo que chamamos de cultura e aquilo que chamamos de religião de um povo não são dois aspectos da mesma coisa: a cultura sendo [...] a encarnação da religião de um povo” (Eliot, 1949, p. 27, tradução nossa). 
A definição de Eliot faz bastante sentido, por exemplo, no estudo da doutrina do Destino Manifesto - abordada com mais detalhes no próximo capítulo -, surgida nos EUA no século XIX. A doutrina fundia a cultura expansionista americana a valores quasi-religiosos dentro de uma única perspectiva, forjando uma espécie de religião secular.

De volta à definição de cultura, Eliot (1949, p.26, tradução nossa) elabora, grandiosamente, que “cultura pode até ser descrita simplesmente como aquilo que faz a vida valer a pena ser vivida”.

Na visão realista, a palavra cultura soa frívola e desimportante, apesar de representar quase toda a atividade humana na Terra (ELIOT, 1949, p. 30; WALKER, 1990, p. 3). Entretanto, a incapacidade do realismo em explicar a conjuntura atual e as recentes mudanças estruturais nos força a buscar fontes teóricas alternativas para entender as relações internacionais do século XXI e, em particular, o seu aspecto cultural.

A própria abordagem da diferença entre o $\mathrm{Eu}$ e o Outro, fonte de nacionalismos intolerantes, está fragilizada. A linha separadora entre o Eu e o Outro está cada vez mais indistinta (WALKER, 1990, p. 6).

Na questão étnica, por exemplo, a miscigenação causada pelo fluxo de pessoas tornou, em grande parte do mundo, a diferenciação do Outro absoluto muito menos plausível.

Naturalmente, o racismo e o etnocentrismo ainda são questões extremamente importantes nas relações internacionais contemporâneas, mas não possuem o apoio acadêmico ou científico que já receberam em outros períodos da história (WALKER, 1990, p. 6).

Concomitantemente, não se trata de idealismo ou da existência de uma sociedade internacional. Não existe uma sociedade internacional. O que de fato tem se materializado é um intercâmbio cultural profundo, intenso e veloz - talvez nunca 
antes visto na história - e tão real que tem sido capaz de estremecer as bases de algumas suposições históricas como uma espécie de choque de realidade.

Não obstante, como com qualquer força transformacional, existe um fluxo transformador que segue uma direção específica e fluxos opostos de contestação e resistência.

De onde partem os grandes fluxos transformadores e para onde eles vão é um dos objetos do estudo da globalização cultural, e que será abordado no próximo capítulo como parte do tema abordado pelo presente estudo.

Considerando cultura como a diferença entre o Eu o Outro - mesmo que essa diferença não seja tão clara hoje como já foi - e sabendo que ela representa um conjunto de elementos no campo das idéias, os "elementos intangíveis", que influenciam o mundo físico, partir-se-á agora para a definição utilizada neste estudo.

O objetivo não é limitar demais o conceito, pois como já foi dito no segundo parágrafo da presente seção, é exatamente a amplitude da definição que o fortalece. O estudo não pretende destituir o termo desta característica particular.

Então, para o propósito do presente trabalho, adotar-se-á como definição central a definição elaborada por Held (1999, p. 329, tradução nossa), a qual se encaixa em uma espécie de subconjunto dentro das outras definições mais amplas acima: "a cultura como a experiência dos indivíduos, criativa e vivenciada, e como um corpo de artefatos, textos e objetos [criados com base nessa experiência].”

De acordo com Held (1999, p. 329, tradução nossa), este sentido "abarca os discursos especializados e profissionalizados das artes, os produtos mercantilizados ${ }^{7}$ da indústria da cultura, as expressões culturais espontâneas e não-organizadas da vida cotidiana e [...] as complexas interações entre todos eles.”

\footnotetext{
${ }^{7}$ Do neologismo inglês commodified.
} 
No entanto, quando o texto se referir a "culturas" influenciando umas as outras, em particular no capítulo três, o leitor deverá considerar a definição acima circunscrita às fronteiras de um Estado. Ou seja, culturas nacionais.

O gráfico abaixo é uma tentativa do autor do desta monografia de organizar visualmente os diferentes níveis da definição de cultura apresentados neste capítulo e indicar o escopo abordado no estudo:

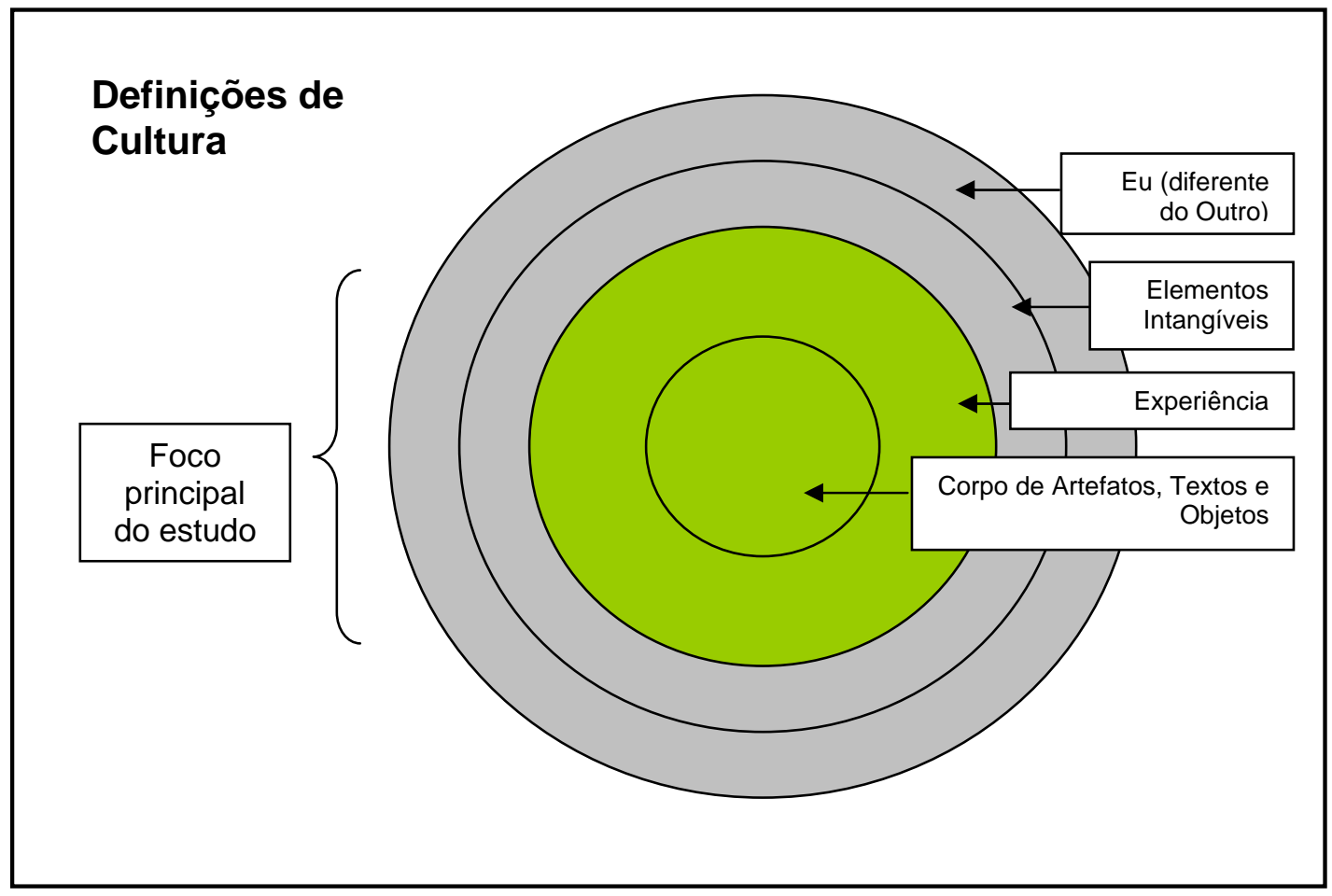

Gráfico 1 - Definições de Cultura. Fonte: João Reino 


\section{GLOBALIZAÇÃO CULTURAL}

Culture is now being defined in terms less of national interests than of a shared set of global ones.

- Paul Jay ${ }^{*}$

\subsection{CONSIDERAÇÕES GERAIS}

A primeira parte deste capítulo orientar-se-á pelo capítulo sete do livro Global Transformations (1999), de David Held e colaboradores, o qual fornece a visão mais ampla e completa encontrada pelo autor desta monografia sobre a globalização cultural, incluindo sua história.

A análise de Held seria suficiente para propiciar ao leitor uma visão abrangente e histórica da globalização da cultura. Entretanto, com o intuito de evitar que a parte se torne uma simples resenha do capítulo, ou heldiana ou extremo, os argumentos encontrados no livro serão complementados ou confrontados com argumentos de outros autores pesquisados, apesar de nenhum outro autor estudado abordar, por si só, todos os aspectos contemplados por Held.

\subsection{GLOBALIZAÇÃO CULTURAL}

De todas as formas de globalização, a cultural é uma das mais diretamente percebidas e vivenciadas (HELD, 1999, p.327). A internacionalização de marcas de consumo, celebridades, música, cinema, moda, etc., são todas manifestações recentes da globalização e presentes na vida cotidiana do cidadão comum.

O total isolamento de uma sociedade, sem sofrer nenhuma influência de outras e sem um corpo de elementos culturais comuns a outras culturas é algo inconcebível nos dias de hoje. Exceto em situações extremas todas as culturas hoje são formas híbridas entre uma cultura nativa local e culturas externas (HEDETOFT, 1999, p. 78).

*2001, p. 32 
Não obstante, apesar de visível, a globalização cultural é difícil de ser estudada devido ao seu caráter subjetivo e de difícil quantificação. Assim como outras formas de globalização, ela tende a ser mais estudada pelos seus impactos.

Diante disso, Held (1999, p.327) identificou três categorias amplas de argumentos sobre os impactos da globalização cultural:

Para ele, existem os hiperglobalizadores, ou aqueles que preveem a globalização cultural como a homogeneização das sociedades sob os auspícios da cultura popular americana e consumismo ocidental, ou seja, a americanização do mundo.

Os hiperglobalizadores são questionados pelos céticos, que destacam a porosidade e insubstancialidade das culturas globais em comparação às culturas nacionais, e lembram a importância que tiveram as diferenças culturais nas relações e conflitos internacionais.

E ainda existe a posição transformacionalista, que vê a formação de híbridos culturais a partir da miscigenação de culturas e povos.

As categorias acima são amplas porém válidas para classificar alguns dos argumentos estudados para este trabalho. Friedman (2009), por exemplo, alerta seus leitores sobre o perigo da hiperglobalização, mas se coloca em uma posição transformacionalista ao defender a diversidade sobre a homogeneidade (2009).

Hedges (2010) e Lanier (2006) são contra a hiperglobalização, mas acreditam que ela está acontecendo agora, principalmente do ponto de vista do consumismo ocidental.

Eliot (1949, p. 62, tradução nossa) se coloca na posição do cético quando afirma que "uma cultura mundial, que fosse apenas uma cultura uniforme, não seria cultura alguma. Teríamos uma humanidade desumanizada”. E enfatiza o valor das culturas locais. 
Além dessa categorização, Held faz uma análise histórica da globalização cultural dividida em cinco partes cronologicamente organizadas. O restante desta seção irá apresentar e discutir as quatro primeiras partes da análise.

\subsubsection{Primeira parte}

A existência de fluxos e instituições transregionais, transcivilizacionais e transcontinentais - globalização cultural - possui raízes históricas profundas. (HELD, 1999, p. 328, tradução nossa)

Para Held, a globalização cultural não é um fenômeno recente. A sua história é longa e está diretamente conectada à difusão do comércio e às migrações globais. De fato, ele argumenta que o verdadeiro pico da globalização cultural, aquele momento da história onde as populações foram mais influenciadas por outras culturas, ocorreu durante o período de expansão das grandes religiões e dos grandes impérios.

A expansão das grandes religiões certamente moldou culturas. Para Eliot (1949, p.26, tradução nossa), os dois aspectos, religião e cultura, são indissociáveis: “o desenvolvimento de cultura e o desenvolvimento de religião [...] não podem ser claramente isolados um do outro”. Eliot ainda argumenta que a própria expansão do cristianismo se beneficiou do fato de ter encontrado em seu caminho uma cultura religiosa em declínio.

No que concernem os grandes impérios, a influência cultural era uma questão estratégica. Meios militares não eram suficientes para manter grandes populações, dispersas em vastas extensões territoriais, sob controle por muito tempo. A cultura servia como um elo de conexão e uma forma de controlar tais populações. Segundo Held (1999, p.334), os impérios que prosperaram foram, inevitavelmente, aqueles cuja extensão de seus poderes militar e político foi reforçada pelo alcance do poder cultural. 


\subsubsection{Segunda parte.}

[...] a partir do século XVIII em diante a centralidade dessas formas antigas de globalização cultural se deslocou, por um lado, devido ao surgimento do Estado-nação, culturas nacionais e instituições culturais nacionais, e por outro, devido ao desenvolvimento de difusão de novas ideologias ocidentais [...]: em particular o liberalismo, o socialismo e a ciência. (HELD, 1999, p. 328, tradução nossa)

O imperialismo ocidental do século XVI ao século XX criou grande parte da infra-estrutura de difusão cultural necessária para a disseminação do verdadeiro conteúdo que estava para ser disseminado a partir do século XVII: a cultura nacional moderna, os nacionalismos e as ideologias e discursos transnacionais (HELD, 1999, p.336).

A partir daí, os impérios foram sendo substituídos pelo imperialismo cultural sustentado por uma bandeira nacional. O Estado, em particular, se apropriou da formação de identidades e culturas nacionais em seus próprios territórios e institucionalizou o imperialismo cultural em territórios de seu domínio, com o objetivo de controlar, suprimir ou erradicar identidades concorrentes e nacionalismos periféricos (HELD, 1999, p. 338).

Foi o período em que os Estados europeus recém-formados e soberanos buscavam conquistar sociedades periféricas mais “atrasadas” geralmente com propósitos comerciais, mas sob a justificativa de abri-las para o “cristianismo” e a “civilização” (GUIMARÃES, 2007, p. 3).

Alguns autores debatem que as forças globalizadoras recentes são ameaças ao monopólio do Estado-nação como "princípio organizador político e cultural da modernidade industrial de massa” (HEDETOFT, 1999, p.72, tradução nossa). Esta questão será abordada mais tarde, na quarta parte do argumento de Held, onde ele mesmo põe em xeque a centralidade do estado na globalização cultural. 


\subsubsection{Terceira parte}

Apesar das alegações cosmopolitas e internacionalistas dessas ideologias e modos de pensar, e do desenvolvimento de novas tecnologias de transmissão cultural [...], o equilíbrio de poder cultural efetivo durante a maior parte dos últimos duzentos anos permaneceu nas mãos de Estadosnação e culturas nacionais. (HELD, 1999, p. 328, tradução nossa)

Para Held (1999, p. 339), os movimentos do liberalismo, socialismo e da ciência, apesar de se declararem como movimentos universais e terem tido amplo alcance além das fronteiras norte-americanas e européias, onde foram concebidos, retinham particularismos históricos e geográficos.

O apelo universal comum a eles mascarava, explícita ou implicitamente, interesses nacionais. A Inglaterra, por exemplo, passou a defender o liberalismo, na forma de livre comércio, uma vez que os interesses econômicos criados pela Revolução Industrial britânica passaram a considerar o mercantilismo "irrelevante ou danoso" (FRIEDEN, 2006, p.19).

\subsubsection{Quarta parte}

Na era contemporânea, uma série de transformações tecnológicas e institucionais alteraram novamente o equilíbrio. Novas tecnologias de telecomunicações e o surgimento de corporações internacionais de mídia, entre outros fatores, geraram fluxos culturais globais cujo alcance, intensidade, diversidade e rápida difusão excedem o de eras anteriores. Por conseguinte, a centralidade de culturas nacionais, identidades nacionais e suas instituições estão em xeque. (HELD, 1999, p. 328, tradução nossa)

Nesse ponto, Held (1999) fala das infraestruturas de produção, transmissão e recepção cultural. Ele argumenta que analisar a globalização cultural apenas do ponto de vista das interações humanas e da espontaneidade seria considerá-la dominada pelo “proselitismo e evangelização”. Segundo Held (1999, p. 330, tradução nossa), "práticas culturais podem ser, e são, ativamente impostas em locais distantes de sua produção". 
Chega-se então na questão do que ele chama de modos de interação, ou seja, as formas dominantes pela qual a globalização cultural opera: da imposição à emulação e difusão. “O movimento e a adoção de práticas culturais podem ocorrer pela importação e reprodução ativas” (HELD, 1999, p. 330, tradução nossa).

Hedetoft (1999) questiona se os novos fluxos de globalização cultural ameaçam o Estado-nação, e conclui que o que existe em comum nos debates travados na década de 1990 sobre o assunto é a percepção de que está cada vez mais difícil distinguir questões de política internacional de questões de cultura e identidade. Para ele, há uma pressuposição quase universal de que existe uma tensão entre duas forças opostas: a coesão do Estado-nação e os processos globais.

Hedetoft (1999) vai além e descreve alguns processos inter-relacionados que estão de fato desafiando a estabilidade do Estado-nação, entre eles a integração regional e os novos processos transnacionais e interculturais. Entretanto, conclui dizendo que o verdadeiro paradoxo é que a reação do nacionalismo ameaçado pode ser uma reinvenção - e até o fortalecimento - de si mesmo, para sobreviver em circunstâncias ditadas pelas relações entre "forças transnacionais, interculturais e modeladoras de identidade” (HEDETOFT, 1999, p. 79, tradução nossa).

Rosenau (2000, p. 376) observa que há "uma tendência importante do atual cenário mundial [que] implica certa diminuição da autoridade do Estado”. Segundo ele, os Estados ainda predominam - seus interesses, conflitos, barganhas, etc. - mas a tecnologia eletrônica e de transporte tem reduzido essa predominância e ampliado a "autonomia das diversas coletividades existentes no mundo multicêntrico, multiplicando o número e o tipo das transações realizadas através das fronteiras nacionais sem participação ou influência dos Estados” (ROSENAU, 2000, p. 376).

Em relação às novas tecnologias mencionadas por Held (1999) e utilizadas para a difusão cultural, ele destaca as telecomunicações em geral, o rádio, a televisão e, mais recentemente, a Internet. Grande parte desses meios é controlada por grandes conglomerados empresariais de mídia. 
Para Hedges (2010), a Internet como tecnologia de propagação de cultura e informação está sendo apropriada por interesses corporativos. De acordo com ele, estamos vivendo a era do "Estado corporativo", onde o Estado - em particular seus governantes - se submete aos interesses das grandes corporações cujo objetivo final é a maximização dos lucros.

Nessa nova realidade não está claro quem detém o poder: se o Estado ou as grandes corporações. No caso da cultura, os grandes conglomerados de mídia.

\subsection{A GLOBALIZAÇÃO CULTURAL CONTEMPORÂNEA E OS ESTADOS UNIDOS}

A globalização cultural contemporânea é a ocidentalização do mundo. Existe pouca ou nenhuma dúvida de que globalização cultural hoje é a disseminação de valores e artefatos culturais - e estilos de vida - ocidentais. Mesmo o termo “ocidentalização” ainda é uma generalização. Numa observação mais cautelosa pode-se chegar à percepção de que globalização cultural é um sinônimo para a americanização do mundo.

Não obstante, a americanização global não significa a homogeneização cultural de todo o sistema internacional. A queda do Muro de Berlim e o fim da URSS levantaram suspeitas de que não haveria mais barreiras ao domínio cultural norte-americano (FRIEDMAN, 2009, p. 435). Os Estados Unidos estariam livres para impingir sua cultura em todo o planeta e nada nem ninguém os impediria.

De fato, o temor era real. Os Estados Unidos estavam bem preparados para tirar vantagem das mudanças que ocorreram naquela década. Como Friedman (2009, p. 435-436) coloca:

[...] os fabricantes e prestadores de serviços com base no território americano, as marcas americanas e os cineastas americanos, os cantores americanos e os artistas americanos, os estilistas de moda americanos e as cadeias de fast-food americanas estavam mais bem posicionados para tirar

\footnotetext{
${ }^{8}$ Do original em inglês: corporate State. Hedges fala do Estado corporativo em entrevista cedida para a GloboNews dia 26 de janeiro de 2010. Disponível em: <http://especiais.globonews.globo.com/milenio/2010/01/26/o-perigeu-do-imperio-da-ilusao $>$ Acesso em 25 jan. 2010.
} 
vantagem [da globalização]. Eles eram os primeiros na largada, e parecia inevitável e incontrolável que tirassem vantagem do mundo plano para homogeneizar sua cultura.

Passados mais de vinte anos, a homogeneização cultural não ocorreu. Porém a força de influência cultural americana permanece incontestavelmente estável e forte. A infraestrutura de produção e distribuição de bens culturais, apresentada no quarto argumento de Held (1999, p. 330), está nas mãos de empresas americanas. A indústria cultural americana é a mais lucrativa do mundo, sua expansão sistemática faz parte de um projeto empresarial e jamais será interrompida, a não ser que passe a dar prejuízo a seus investidores (HERMAN \& CHOMSKY, 2003, cap. 1).

Pode-se argumentar que uma cultura não pode ser impingida a outra, que é necessário certo grau de aceitação natural na cultura receptora. Certamente, parte da influência cultural ocorre naturalmente. A cultura americana é instigante, dinâmica, e gera frutos de interesse universal.

Não obstante, a aceitação também pode ser manipulada. A cultura pode ser mercantilizada, precificada e apresentada como um produto esteticamente aceitável. Na publicidade o processo é conhecido como estetização haugiana (MARSHALL) e não há porque acreditar que ele não possa ser aplicado à disseminação de cultura.

Um exemplo de esforço deliberado feito pelo governo americano para estender o seu poder através da aceitação da cultura ocorreu na década de 1950, quando a CIA criou uma operação secreta para combater o comunismo pela influência cultural. Através do Office of Policy Coordination ${ }^{9}$ (OPC) a CIA organizou o Congress for Cultural Freedom ${ }^{10}$ com o objetivo de atrair a esquerda não-comunista americana e impedir o avanço do comunismo desmentindo a idéia de que o regime comunista era mais favorável ao desenvolvimento cultural do que a democracia burguesa (CIA, 2007).

O objetivo do OPC era mostrar aos europeus o que havia de melhor nos Estados Unidos em termos culturais. A iniciativa, além de servir como uma espécie

\footnotetext{
${ }^{9}$ Escritório de Coordenação de Políticas

${ }^{10}$ Congresso para a Liberdade Cultural
} 
de mostruário da cultura americana, pavimentou o caminho para a aceitação de artefatos culturais que mais tarde fariam parte do arcabouço de sustentação à americanização. Uma personagem proeminente de todo esse movimento foi o professor de filosofia Sidney Hook (apud CIA, 2007, tradução nossa), que fez a célebre afirmação em 1949:

Dê-me um milhão de dólares e mil pessoas dedicadas, e eu garanto gerar uma onda de inquietude democrática nas massas - sim, mesmo entre os soldados - do império de Stalin que todos os seus problemas, por um longo período de tempo, serão internos. Eu consigo achar as pessoas. ${ }^{11}$

Ou seja, com um milhão de dólares - ou muito mais, no caso dos grandes conglomerados de mídia - e um grupo de pessoas dedicadas - trabalhadores que dependem do lucro da indústria para receberem seus salários - é possível fazer um esforço bem planejado de promoção cultural, sustentado por técnicas avançadas de marketing, psicologia, publicidade e distribuição.

$\mathrm{Na}$ verdade, as aspirações norte-americanas de imposição e exportação cultural são antigas e já se faziam notar desde a formação dos Estados Unidos e a conquista do oeste. A doutrina do Destino Manifesto, na primeira metade do século XIX, fornecia a base de sustentação moral e cultural para o expansionismo americano rumo ao interior do continente, em detrimento das populações nativas que ali habitavam (BRAUER, 1999, p. 379).

Para a doutrina, o povo americano é o eleito de Deus e sua expansão nada mais é do que a manifestação da vontade divina. Expressões como a "Nova Israel de Deus” ou o “Novo Éden”, em referência aos EUA, foram freqüentemente utilizadas na história americana, inclusive por Chefes de Estado como parte das justificativas para seus propósitos expansionistas e intervencionistas (GALTUNG, 1999, p.119; BRAUER, 1999, p. 380; COLES, 2002).

Não se trata de um argumento utilizado explicitamente nos dias de hoje, mas as semelhanças ideológicas com fatos recentes, como a Guerra ao Terror do ex-

\footnotetext{
${ }^{11} \mathrm{CF}$ : "Give me a hundred million dollars and a thousand dedicated people, and I will guarantee to generate such a wave of democratic unrest among the masses--yes, even among the soldiers- of Stalin's own empire, that all his problems for a long period of time to come will be internal. I can find the people.".
} 
presidente George Bush - associada a sua religiosidade (ARRAES, 2008, p. 24) - e a subsequente invasão do Iraque em 2006, sugerem que a doutrina segue influenciando pensamentos imperialistas contemporâneos (COLES, 2002).

Redundâncias à parte, a exportação da cultura americana faz parte da própria cultura americana. Trata-se mais um item do instrumentário expansionista nacional.

Hamid Mowlana (1990, p. 224, tradução nossa) afirma que “o campo de batalha da política internacional se deslocou do nível geográfico e físico para os níveis ideológico, comunicacional e cultural”.

Tal deslocamento foi bastante visível no século $\mathrm{XX}$ e os avanços nas tecnologias de telecomunicação e informação tendem a torná-lo ainda mais perceptível no século XXI. Obviamente, os Estados Unidos não poderiam deixar de ocupar esse campo de batalha e tem feito grandes esforços para tal.

Hedges (2010) afirma que a partir do momento que a disseminação cultural americana se desconectou de questões morais e ideológicas e se fixou no mercado e na obtenção de lucro pelas grandes corporações - e o Estado corporativo se consolidou - o país corre o risco de ser levado à ruína.

O resultado, de acordo com Hedges (2010), poderá vir a ser uma espécie de totalitarismo americano no qual as corporações exercem todo o poder, mas de forma imperceptível, amortizada pelo governo de fachada, submisso aos interesses das mesmas.

A ruína ainda não chegou aos Estados Unidos, e esta é apenas uma hipótese. Enquanto isso, o país parece seguir firme em suas iniciativas de exercer o poder pela influência cultural. Entretanto, a tecnologia mudou. A Internet se consolidou e abriu novos canais de comunicação de massa. As expectativas ao seu redor são muitas, mas será que a Internet, como tecnologia recente de propagação de conteúdo cultural, é ou será uma força capaz de deslocar a direção do fluxo da globalização cultural? Será que a Internet pode ajudar culturas menores e menos influentes a se protegerem ou até mesmo se expandirem perante o "rolo compressor” americano? Ou será que 
nada mudou e a Internet é apenas mais um meio utilizado a serviço da infraestrutura cultural americana? O próximo e último capítulo aborda algumas dessas questões sob a luz da literatura pesquisada e dos achados identificados na pesquisa de tráfego. 


\section{A INTERNET E A GLOBALIZAÇÃO CULTURAL}

The beauty of the Internet is that it connects people. The value is in the other people. If we start to believe that the Internet itself is an entity that has something to say, we're devaluing those people and making ourselves into idiots.

- Jaron Lanier*

\subsection{CONSIDERAÇÕES GERAIS}

A Internet foi criada em 1969 como um projeto da Advanced Research Projects Agency (ARPA, hoje chamada de DARPA - Defense Advanced Research Projects Agency), do Departamento de Defesa dos Estados Unidos (LEINER).

Na época, a ARPANET, como foi originalmente batizada, era uma tentativa do governo americano em recuperar a liderança tecnológica logo após o lançamento do satélite Sputnik pelos Russos. A idéia era criar uma rede de comunicação que continuasse disponível mesmo no caso de destruição de um dos seus nós por ataque nuclear. Os roteadores direcionariam o tráfego para os caminhos disponíveis (LEINER).

Inicialmente, a ARPANET conectava apenas quatro grandes computadores em quatro universidades americanas (UCLA, Stanford Research Institute, USCB e University of Utah), mas logo atraiu o interesse de outras universidades. A rede ainda não possuía uma interface amigável e era apenas utilizada por cientistas, engenheiros e especialistas.

Em 1974 o termo "Internet” foi utilizado pela primeira vez, e em 1989 o primeiro serviço comercial de correspondência eletrônica (e-mail) foi implementado. Entretanto, apenas uma "coincidência de eventos" (FRIEDMAN, 2009, p. 76) no início da década de 1990 permitiu a popularização da Internet como conhecemos hoje e a possibilidade de disseminação de conteúdo globalmente.

O primeiro desses eventos foi o desenvolvimento da World Wide Web, pelo cientista britânico TIM Berners-Lee, como uma forma de organizar e apresentar o 
conteúdo binário disponível na rede antes inacessível aos leigos (FRIEDMAN, 2009, p. 76).

O segundo foi a criação da ferramenta de navegação, o browser ou navegador, que pela primeira vez apresentou ao público um software de interface simples e amigável através da qual qualquer um podia entrar em "páginas” da Internet e visualizar seu conteúdo.

A abertura da Internet ao público gerou conseqüências sociais ainda pouco estudadas. Não obstante, as promessas e expectativas que desde então tem acompanhado a evolução da rede são geralmente positivas e incluem: a redução de barreiras culturais, o fomento da criatividade e inovação e a democratização da informação.

O presente capítulo é subdivido em três partes, além das considerações gerais. A primeira expõe uma breve análise da infraestrutura de comunicação utilizada pela Internet e a sua capacidade de transmissão de conteúdo.

Em seguida, são apresentados e discutidos alguns argumentos de Thomas Friedman (2009) e Chris Hedges (2010), dois jornalistas americanos com opiniões bastante distintas sobre a Internet e a Globalização Cultural. Alguns argumentos de Jason Lanier (2006) também são acrescentados às considerações de Hedges, já que o primeiro é bastante citado pelo último no artigo analisado para este trabalho.

Finalmente, são expostos números relativos ao tráfego de usuários dos principais websites de notícias dos EUA, Brasil, França e, posteriormente, China, e alguns indicadores econômicos desses países, a fim de se chegar a conclusões sobre os fluxos de informações na rede. As estatísticas e indicadores chineses foram acrescentados ao capítulo apenas por questão metodológica e para melhor ilustrar os resultados da comparação.

\subsection{A REVOLUÇÃO DA FIBRA ÓTICA}

Os cabos de transmissão de sinais sempre foram a espinha dorsal das telecomunicações, desde a invenção do telégrafo em 1837. Segundo Held (1999, p. 
343), os satélites conseguiram atrair parte do volume de tráfego que circulava nos cabos de telecomunicações marítimos nos anos 1970. Entretanto, os novos cabos de fibra ótica instalados nas décadas de 1980 e 1990 desafiaram a capacidade de tráfego dos satélites nas rotas de comunicação mais intensa.

A fibra ótica, com sua enorme capacidade de transmissão de sinal, marcou o início de uma nova era nas telecomunicações de longa distância. Para se ter uma idéia do crescimento exponencial do tráfego, em 1983 havia pouco mais de 18.000 linhas de voz transatlânticas. Em 1996, menos de dez anos após a colocação do primeiro cabo de fibra ótica transatlântico, o número total de linhas disponíveis em cabos transoceânicos já era de 1.264.000. Em 1997, um único cabo era capaz de comportar 600.000 linhas de voz (HELD, 1999, p.343).

Com efeito, a malha de cabos instalados e disponíveis tem uma relação direta de causa e efeito com o advento da Internet. Ela viabilizou a sua existência e expansão, pois os mesmos cabos que antes transmitiam apenas voz passaram a ser utilizados para a transmissão de dados.

A fibra ótica abriu as portas para a troca internacional de conteúdo digital cada vez mais complexo, na forma de texto, imagem, som e vídeo. Ao mesmo tempo, o sucesso da abertura da Internet ao público e a bolha das empresas "pontocom” da década de $1990^{12}$ encorajou empresas de telecomunicações a expandirem ainda mais suas redes de cabeamento.

A expansão dessa infraestrutura de comunicação começou nos EUA mas extrapolou suas fronteiras e aproximou regiões antes separadas pelo espaço e tempo. Para alguns autores, a expansão evidenciou ainda mais o fenômeno de compressão

\footnotetext{
${ }^{12}$ Na década de 1990 a especulação sobre o crescimento da Internet atingiu patamares altíssimos. A expectativa de lucro era grande e as empresas "ponto-com", como eram chamadas os empreendimentos que forneciam soluções e serviços pela Internet, foram super-valorizadas nas bolsas de valores americanas. Os venture capitalists, ou capitalistas de riscos, investiam somas gigantescas em novas entrantes; e as empresas de telecomunicações, a fim de obter parte dos possíveis lucros, expandiam suas infraestruturas rapidamente. A exaltação não passava de uma "bolha" que estourou em 2000. Inúmeras empresas faliram e muito dinheiro foi perdido. Entretanto, até que a bolha estourasse, muito investimento foi feito em infraestrutura de comunicação (cabos de fibra-ótica) que depois permaneceu ociosa e acabou sendo disponibilizada a preços muito inferiores ao custo de instalação. (Nethistory.com; Theinvestorsjournal.com)
} 
tempo-espacial descrito no primeiro capítulo (HELD, 1999, p. 330; HARLEY apud PRADO, 2006; GIDDENS apud PRADO, 2006).

Hoje, o volume de dados em circulação na Internet por segundo é gigantesco e crescente, como ilustra o gráfico abaixo elaborado pela TeleGeography ${ }^{13}$ :

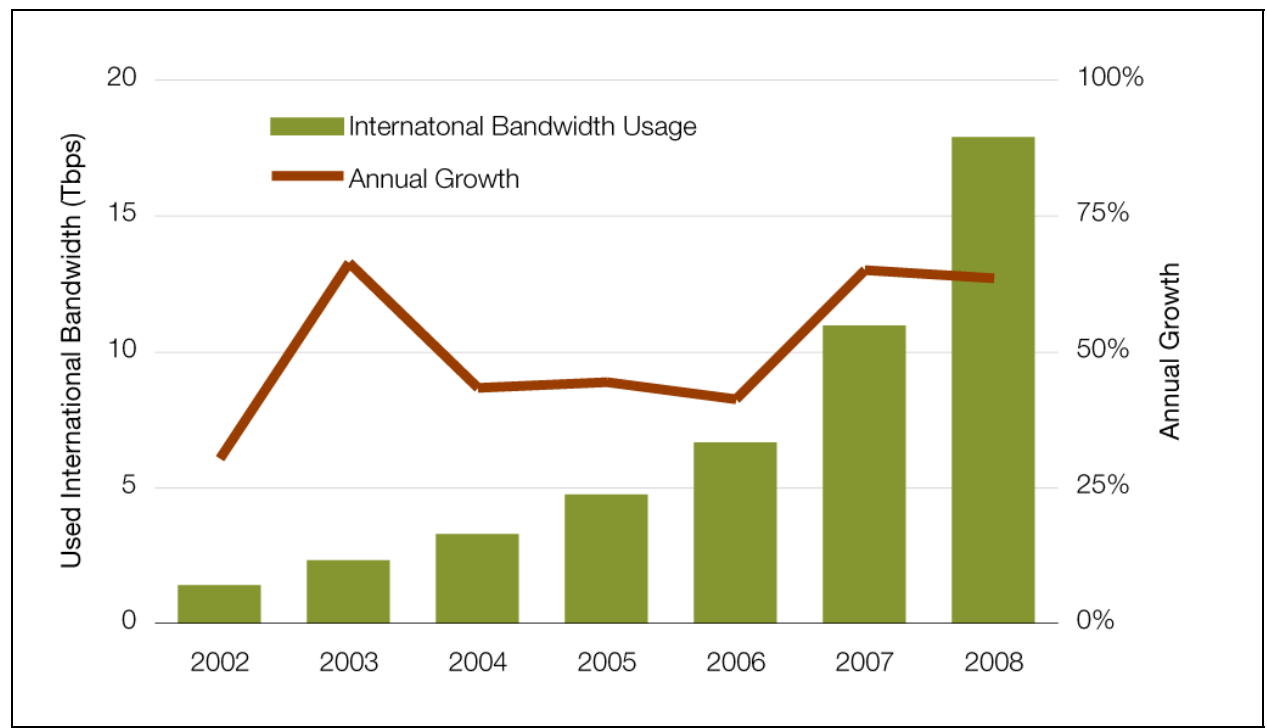

Gráfico 2 - Utilização Internacional de Largura de Banda. Fonte: TeleGeography ${ }^{14}$

De acordo com o gráfico, em 2002 circulavam na rede aproximadamente 2 Terabits de dados por segundo, em 2008 esse volume já alcançava os 18 Terabits. Um crescimento de $600 \%$ em apenas seis anos.

Essa quantidade massiva de bits transporta conteúdo; e entre comunicações corporativas, transações financeiras e intercâmbios operacionais triviais encontramse artigos de jornais, entrevistas, produções em vídeo, programas de rádio, podcasts, etc., os quais carregam informação e cultura.

O volume de troca está longe do trivial e faz com que a Internet como mídia propagadora de informação e cultura não possa ser ignorada. É possível que a

\footnotetext{
${ }^{13}$ A TeleGeography é a divisão de pesquisa da PriMetrica Inc. e é especializada em pesquisa sobre a utilização da largura de banda na Internet mundialmente.

${ }^{14}$ Disponível em: <http://www.telegeography.com/product-info/gb/>. Acesso em 10 mar. 2010.
} 
Internet hoje transmita mais palavras por segundo do que qualquer outro meio de difusão cultural, como a televisão, o rádio ou o cinema. Até mesmo porque, dada a convergência tecnológica atual, diversas emissoras de televisão e rádio estão transmitindo sua programação também pela $W e b$, além dos meios tradicionais.

Não obstante, a disseminação de conteúdo não é equilibrada. A própria colocação dos cabos e a infraestrutura disponível não é igual entre as regiões. Até 2005, as conexões diretas sul-sul eram praticamente inexistentes, como ilustra o gráfico de largura de banda disponível entre as regiões:

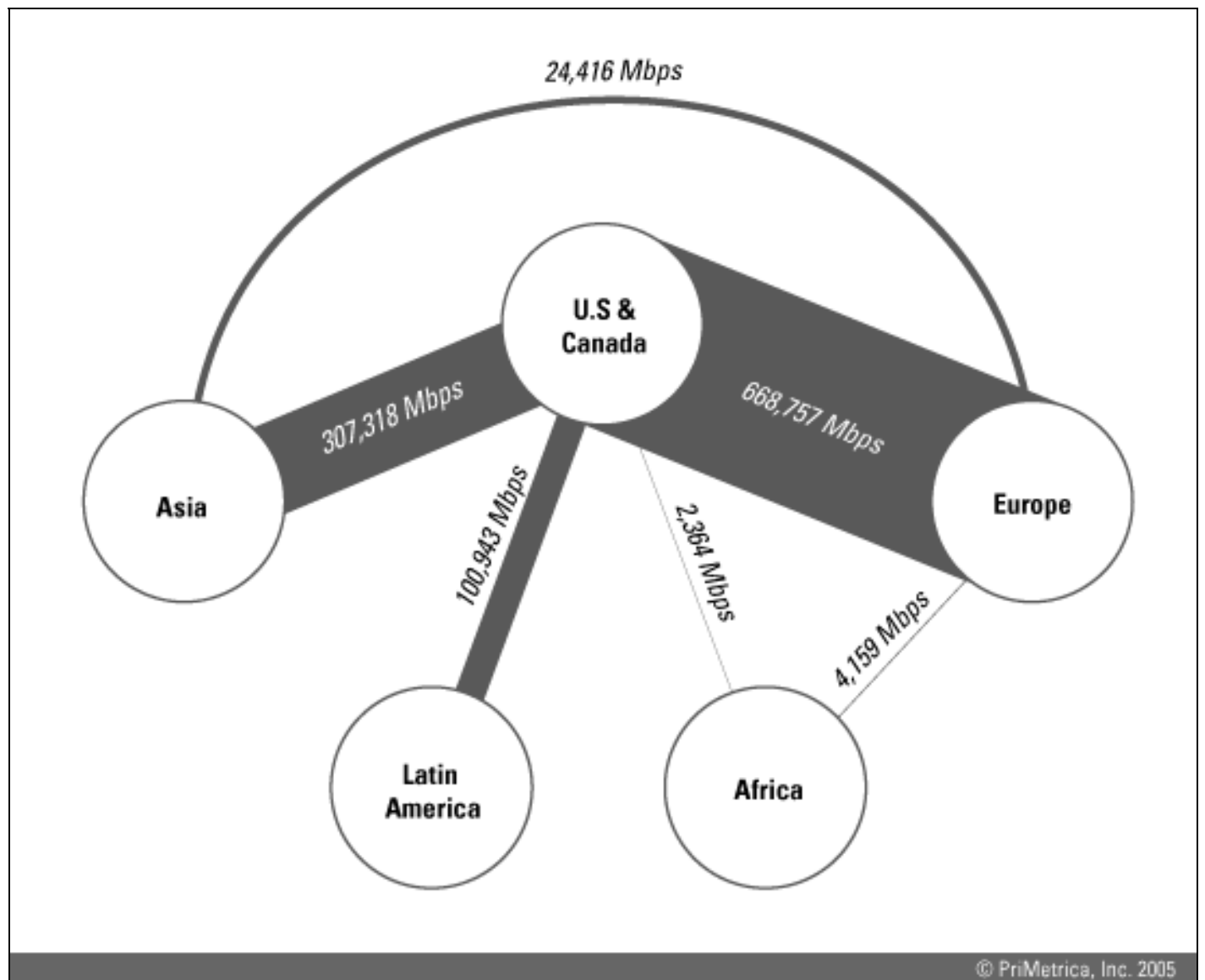

Gráfico 3 - Largura de Banda Disponível Interregionalmente, 2005. Fonte: TeleGeography ${ }^{15}$

O gráfico ilustra bem a intensidade de tráfego entre as regiões e o desequilíbrio da infraestrutura disponível. Mesmo se internautas na África, por

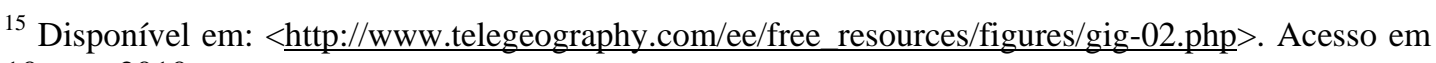
10 mar. 2010.
} 
exemplo, tivessem os recursos e quisessem navegar pela Internet na mesma intensidade que os americanos, gerando e absorvendo conteúdo, não conseguiriam porque a infraestrutura inexiste.

O tráfego máximo que podia circular a partir da África em 2005, como ilustra o gráfico, era de 6523Mbps, em comparação com os quase 700 mil Mpbs que podiam circular diretamente só entre os EUA e a Europa. Proporcionalmente, os números não devem ser muito diferentes hoje.

Entretanto, o desequilíbrio é apenas um resultado da demanda. O fluxo de conteúdo na Internet é um reflexo do fluxo de conteúdo em outras mídias, que existiam antes da rede. Friedman (2009) acredita que isso vai mudar, que a Internet está criando a plataforma comum para que um dia todos os países possam projetar suas culturas online de forma mais equilibrada. Ele chega a comparar a Internet a uma massa de pizza, onde cada cultura poderá colocar os “ingredientes" e “temperos” que desejar (FRIEDMAN, 2009, p.437).

A comparação é interessante e chega a fazer sentido, mas o que é de fato relevante no estudo da globalização cultural, e mantendo a analogia, é quem vai comer todas essas pizzas. Será que todas serão absorvidas? Ou será que alguns poucos pizzaiolos permanecerão bastante populares entre os consumidores e outros terão suas pizzas apodrecendo na Web sem nunca serem consumidas, nem sequer vistas? Estas perguntas serão respondidas nas próximas duas seções deste capítulo.

\subsection{FRIEDMAN, HEDGES E LANIER}

Esta seção apresenta as visões de dois jornalistas, Thomas L. Friedman (2009) e Chris Hedges (2010). Ambos americanos mas com posições bastante distintas sobre cultura e Internet. Apesar do artigo de Hedges (2010) estudado para este trabalho não falar explicitamente da globalização cultural, o texto traz alguns pontos de vistas interessantes sobre cultura de massa e a Internet que podem ser extrapolados para o ambiente da globalização e analisados contra certos argumentos de Friedman sem detrimento da comparação. 
Jason Lanier (2006) é outro autor com visões divergentes das de Friedman (2009), e bastante citado por Hedges (2010). Por conseguinte, alguns argumentos de Lanier também serão utilizados nesta análise como argumentos de apoio, ou complementares, aos de Hedges (2010).

Friedman diz em seu livro O Mundo é Plano (3 ed., 2009, p. 9-10) que a globalização está vivendo um processo de “achatamento”. Ele utiliza a noção de achatamento "para descrever como muito mais pessoas podem ligar e usar, competir, conectar e colaborar a partir de um poder mais igualitário do que antes”, e diz que é esse o "impacto essencial das mudanças tecnológicas que ocorrem hoje em dia”.

Friedman (2009, p. 10) deixa claro na introdução da terceira edição que não se refere à igualdade no sentido de rendas iguais, mas sim às forças de achatamento que, no seu entender, "estão conferindo poder a um número cada vez maior de indivíduos”.

Hedges (2010, nossa tradução), por sua vez, argumenta o oposto. Em seu artigo The Information Super-Sewer ${ }^{16}$, ele diz que a Internet se corrompeu e é hoje “mais uma ferramenta seqüestrada pelo interesse corporativo para acelerar nosso declínio cultural, político e econômico”. Ou seja, o poder não está nas mãos das pessoas, mas sim de grandes corporações, como acontece com os outros meios de comunicação, dominados há muito tempo por conglomerados de mídia que determinam o que iremos assistir ou ouvir (e, no caso da Internet, fazer o download).

Para Friedman (2009, p. 436), a "plataforma do mundo plano”, como ele designa as forças e tecnologias que promovem o "achatamento" do mundo, "embora tenha o potencial de homogeneizar culturas, também tem [...] um potencial ainda maior para aumentar a diversidade em um nível que o mundo jamais viu”.

Friedman (2009) é um otimista, e de todos os ângulos pelos quais ele enxerga a Internet é capaz de ver resultados positivos e o triunfo da diversidade sobre a homogeneidade. Ele garante que o fato de as pessoas poderem publicar seus

\footnotetext{
16 “O Super Esgoto da Informação”, uma crítica à definição comum da Internet como The Information Super-Highway (A Super Auto-estrada da Informação).
} 
próprios conteúdos na Web, em sites de divulgação de conteúdo, como o YouTube (para vídeos), o Flickr (para fotos) ou o Blogger (para textos), irá tornar possível o que ele chama de "globalização do local”, que é quando um conteúdo produzido localmente é capaz de ser assistido e absorvido por audiências globais.

Com efeito, a publicação de conteúdo existe e é real na Web. Qualquer pessoa com acesso a um computador e uma linha telefônica pode fazer o upload de material original, criado por ela mesma.

No entanto, Hedges (2010) e Lanier (2006) argumentam que, ao invés de promover a criatividade, os sites de divulgação de conteúdo recebem os trabalhos criativos sem remunerar seus autores e os utilizam como “iscas" para atrair anunciantes. Para Lanier (apud Hedges, 2010, tradução nossa), o material original publicado na Internet é “copiado, misturado, anonimizado, analisado e transformado em tijolos de um forte alheio para apoiar um esquema de publicidade” e para Hedges (2010, tradução nossa) a Internet está “destruindo o trabalho criativo”.

Um grande problema para Hedges (2010) é o fato de a grande maioria dos sites não pagar por conteúdo. De acordo com ele, os únicos capazes de obter uma renda decente com a Internet são os profissionais de propaganda e a alta gerência corporativa. Jornalistas, fotógrafos, músicos, desenhistas, cineastas, etc., estão todos perdendo dinheiro com a facilidade de disseminação de conteúdo proporcionada pela a Web combinada à proteção ineficiente da propriedade intelectual.

Friedman (2009, p. 438) afirma que "as forças da particularização parecem agora tão fortes quanto as forças da homogeneização”, enquanto Hedges (2010) e Lanier (2006) acreditam que estamos testemunhando o triunfo da "hive mentality", ou “mentalidade colméia”. Aparentemente, cada vez mais indivíduos, profissionais ou amadores, estão publicando conteúdo na Web, entretanto, o que poderia ser a superação da homogeneidade pela diversidade se torna coletivismo anônimo.

A “mentalidade colméia” se refere, entre outras coisas, a uma prática comum dos sites de divulgação de conteúdo na qual o trabalho individual não é identificado, ou sua identificação é irrelevante. Todos os trabalhos são agrupados e organizados 
por algoritmos de análise que os classificam de acordo com seu poder de gerar tráfego e, consequentemente, atrair mais anunciantes, dando aos internautas a impressão de terem encontrado algo que estavam realmente procurando quando, na verdade, aquilo é apenas o resultado dos cálculos de um algoritmo capaz de quantificar o interesse coletivo.

Esta técnica é utilizada inclusive em sites aglomeradores de notícias como o Google News e a AOL ${ }^{17}$. Para Lanier (apud Hedges 2010, tradução nossa), o “coletivismo digital [...] está destruindo os últimos vestígios da criatividade e inovação autênticas”.

Hedges (2010, tradução nossa) chama aqueles que acreditam no futuro do coletivismo vasto de “promovedores utópicos da Internet”.

Aparentemente, Friedman (2009) parece se encaixar na categoria, mas após uma análise mais cuidadosa de seus argumentos é possível perceber que ele está ciente dos possíveis efeitos negativos da Internet na cultura global quando diz que "a globalização tem [...] tendências de dar e tirar poder, de homogeneizar e particularizar, de democratizar e de tomar medidas autoritárias”, e está consciente do fato de que "o mundo plano dá poder a forças obscuras tanto quanto a forças da luz" (FRIEDMAN, 2009, p. 441).

Não é fácil tirar conclusões sobre a globalização cultural e a Internet quando os argumentos positivos e negativos estudados são tão válidos e, de certa forma, empíricos. A ambigüidade parece ser a tônica do debate e, aparentemente, trata-se de uma questão de pontos de vistas diferentes sobre o mesmo fenômeno.

A Internet tem o poder de manter culturas vivas, mas não muito diferentemente do que livros abandonados em uma velha biblioteca. Os mecanismos de busca, como o Google e o Bing, que pareciam ser a panacéia para o problema da

\footnotetext{
${ }^{17}$ O site Softpedia publicou um artigo do editor de notícias Web Lucian Parfeni sobre o assunto: “ $A O L$ to Introduce Algorithm-Generated News Stories and Topics: to figure out which stories would generate more revenue” "“A AOL Introduzirá Artigos e Tópicos de Notícias Gerados por Algoritmos: para descobrir quais artigos geram mais receita"). Disponível em $<$ http://news.softpedia.com/news/AOL-to-Introduce-Algorithm-Generated-News-Stories-and-Topics128376.shtml>. Acesso em 02 de mar. de 2010.
} 
vastidão de informação disponíveis na rede, prontos para ajudar os interessados a encontrar aqueles artigos "empoeirados” onde quer que estivessem, parece agora estar nas mãos dos interesses comerciais de seus anunciantes.

Obviamente, o sistema de classificação de páginas do Google sempre foi controlado por algoritmos, e esse é um dos grandes méritos da empresa. Porém uma vez que sua única fonte de renda são os anunciantes é difícil não imaginar que tipos de instruções são injetadas nesses algoritmos pelos programadores: instruções que geram de tráfego, privilegiando a quantidade em detrimento da qualidade.

Como diz Hedges (2010, tradução nossa), “a tecnologia é moralmente neutra. Ela serve aos interesses de quem a controla.” A não ser que o internauta saiba exatamente o que está procurando, os sites aglomeradores de conteúdo, os mecanismos de busca e até mesmo os sites de notícias irão lhe servir apenas exemplares da "mentalidade colméia” e, caso não encontrem resistência, o usuário se tornará mais uma peça do coletivismo digital anônimo.

\subsection{A INTERNET E A INFLUÊNCIA CULTURAL AMERICANA}

A presença cultural americana na Internet parece ser tão forte quanto em outros meios de comunicação internacional. Certamente não se pode falar de uma homogeneização americana, como já foi exposto no capítulo anterior, mas as expectativas de que a Internet promoveria a diversidade cultural e a abertura de diálogo parecem ter se concretizado apenas no que Rosenau (2000) chama de nível micro, entre indivíduos e pequenos grupos, mantendo os grandes fluxos de conteúdo cultural internacional - no nível macro - fluindo na mesma direção que nos meios mais tradicionais.

A fim verificar isso, foi analisado o tráfego (número de visitas ${ }^{18}$ por dia) dos principais sites de notícias e revistas dos Estados Unidos, Brasil e França, e

\footnotetext{
${ }^{18}$ Visitas, ou pageviews em inglês, se refere ao número de vezes que uma página web é vista (aberta pelo navegador). Não se trata de visitantes únicos, o mesmo visitante pode entrar mais de uma vez na mesma página.
} 
identificada a origem do tráfego. Esses números foram confrontados com índices referentes ao poder econômico ( $\mathrm{PIB}^{19}$ ) e qualidade de vida dos países $\left(\mathrm{IDH}^{20}\right.$ ).

Com base nestes dados, tentou-se chegar a conclusões relativas ao poder de penetração dos sites (e, consequentemente, seu conteúdo) em outras culturas e verificar se o poder de penetração cultural tem alguma relação com poder econômico.

A primeira tabela abaixo apresenta o número de visitas diárias aos principais sites de notícias dos três países estudados. A análise foi dificultada pelo fato de os principais jornais brasileiros online não estarem disponíveis em seus próprios domínios na Internet, mas sim dentro do domínio de portais mais amplos, como o UOL.com.br e o GLOBO.com. Devido a isso, a primeira tabela inclui os três primeiros sites disponibilizadores de notícias de cada país; mas nem todos são sites exclusivamente de notícias.

Tabela 1 - Número de visitas aos principais sites de notícias dos três países

\begin{tabular}{lc|lr|lr}
\hline \multicolumn{2}{c|}{ EUA } & \multicolumn{2}{c}{ Brasil } & \multicolumn{2}{c}{ França } \\
\hline Site & Visitas/dia & Site & Visitas/dia & Site & Visitas/dia \\
\hline AOL.com & 26.829 .268 & UOL.com & 14.285 .714 & LeMonde.fr & 1.267 .281 \\
CNN.com & 17.741 .935 & Globo.com.br & 11.578 .947 & TF1.fr & 913.621 \\
NYTimes.com & 11.340 .206 & Terra.com.br & 7.096 .774 & LeFigaro.fr & 787.401 \\
Total & 55.911 .409 & Total & 32.961 .435 & Total & 2.968 .303 \\
\hline
\end{tabular}

Fonte: Websitelookout.com ${ }^{21}$

A próxima tabela mostra o porcentual de visitas oriundas do próprio país de origem do site, ou seja, quantos visitantes da AOL estão nos EUA, quantos visitantes do UOL estão no Brasil, e assim por diante. Esse número nos dá uma idéia do grau de internacionalização do site. Quanto menor for o porcentual mostrado, maior o número relativo de visitas estrangeiras ${ }^{22}$ ao site.

\footnotetext{
${ }^{19}$ Produto Interno Bruto

20 Índice de Desenvolvimento Humano

${ }^{21}$ Em função da variação observada no tráfego optou-se por incluir no trabalho os dados coletados no último dia de observação: 25 de março 2010. Esta data é válida para as três tabelas deste capítulo.

22 Como "visitas estrangeiras" entendem-se o número de vezes que a página é aberta por um navegador instalado em um país diferente do país de origem do site. Os sites de análise de tráfego (Alexa e Websitelookout) conseguem identificar a origem das visitas pelo endereço IP da conexão, que é único e sensível ao país.
} 
Tabela 2 - Porcentual de visitas locais aos sites analisados

\begin{tabular}{lr|lr|lr}
\hline \multicolumn{2}{c|}{ EUA } & \multicolumn{2}{c}{ Brasil } & \multicolumn{2}{c}{ França } \\
\hline Site & Percentual & Site & Percentual & Site & Percentual \\
\hline AOL.com & $76,1 \%$ & UOL.com.br & $91,3 \%$ & LeMonde.fr & $50,3 \%$ \\
CNN.com & $72,4 \%$ & Globo.com & $91,6 \%$ & TF1.fr & $79,8 \%$ \\
NYTimes.com & $68,5 \%$ & Terra.com.br & $91,7 \%$ & LeFigaro.fr & $56,7 \%$ \\
Total $^{23}$ & $76,1 \%$ & Total & $91,5 \%$ & Total & $61,7 \%$ \\
\hline
\end{tabular}

Fonte: Alexa.com e websitelookout.com ${ }^{24}$

De acordo com a tabela, 91,5\% do tráfego dos três sites brasileiros é oriundo do Brasil. Ou seja, apenas 8,5\% das visitas vem de computadores localizados fora do país. Nos sites americanos, 23,9\% de todas as visitas não vem dos Estados Unidos e nos franceses 38,3\% vem de fora da França.

Caso se leve em consideração apenas estes valores, pode-se chegar à conclusão precipitada de que os sites franceses são os mais internacionais. No entanto, o alcance internacional francês é ofuscado por dois fatores:

O primeiro deles é que, após análise mais detalhada, constata-se que uma parte substancial do tráfego estrangeiro dos sites franceses vem de ex-colônias francesas. O site do Le Monde, por exemplo, está entre os trinta mais visitados no Mali e em Madagascar, duas ex-colônias francesas, e mais bem posicionado nestes países do que na França, onde ele é o $59^{\circ}$ site mais visitado.

O LeFigaro.fr também está entre os sites de notícias mais visitados no Líbano, nos Camarões e na Costa de Marfim. Nestes locais a penetração francesa é forte. Porém, no estudo da globalização cultural, a relação cultural entre (ex-)colônia e colonizador ocupa uma categoria a parte, diferente da influência cultural entre países sem passado colonizador, e merece estudo específico não contemplado no presente trabalho.

O segundo fator que reduz o peso do porcentual francês de internacionalização é o número de visitas comparativamente muito baixo. Apesar 38,3\% das visitas a esses três sites virem de fora da França, em números absolutos

\footnotetext{
${ }^{23}$ Os porcentuais totais foram obtidos a partir das médias ponderadas. Ao porcentual de cada site foi atribuído um peso com base no número absoluto de visitas.

${ }^{24}$ Ambas as fontes possuem esta informação e a diferença entre elas não ultrapassou dois pontos porcentuais em nenhum dos sites pesquisados, exceto para o site da revista Istoé (ver nota 25). O valor utilizado no estudo é a média aritmética dos valores coletados nas duas fontes.
} 
elas representam pouco mais de um milhão de acessos, o que é quase irrelevante se comparado aos 23,9\% de visitas estrangeiras aos sites americanos, os quais representam, em números absolutos, mais de 13 milhões de visitas (ver Gráfico 1).

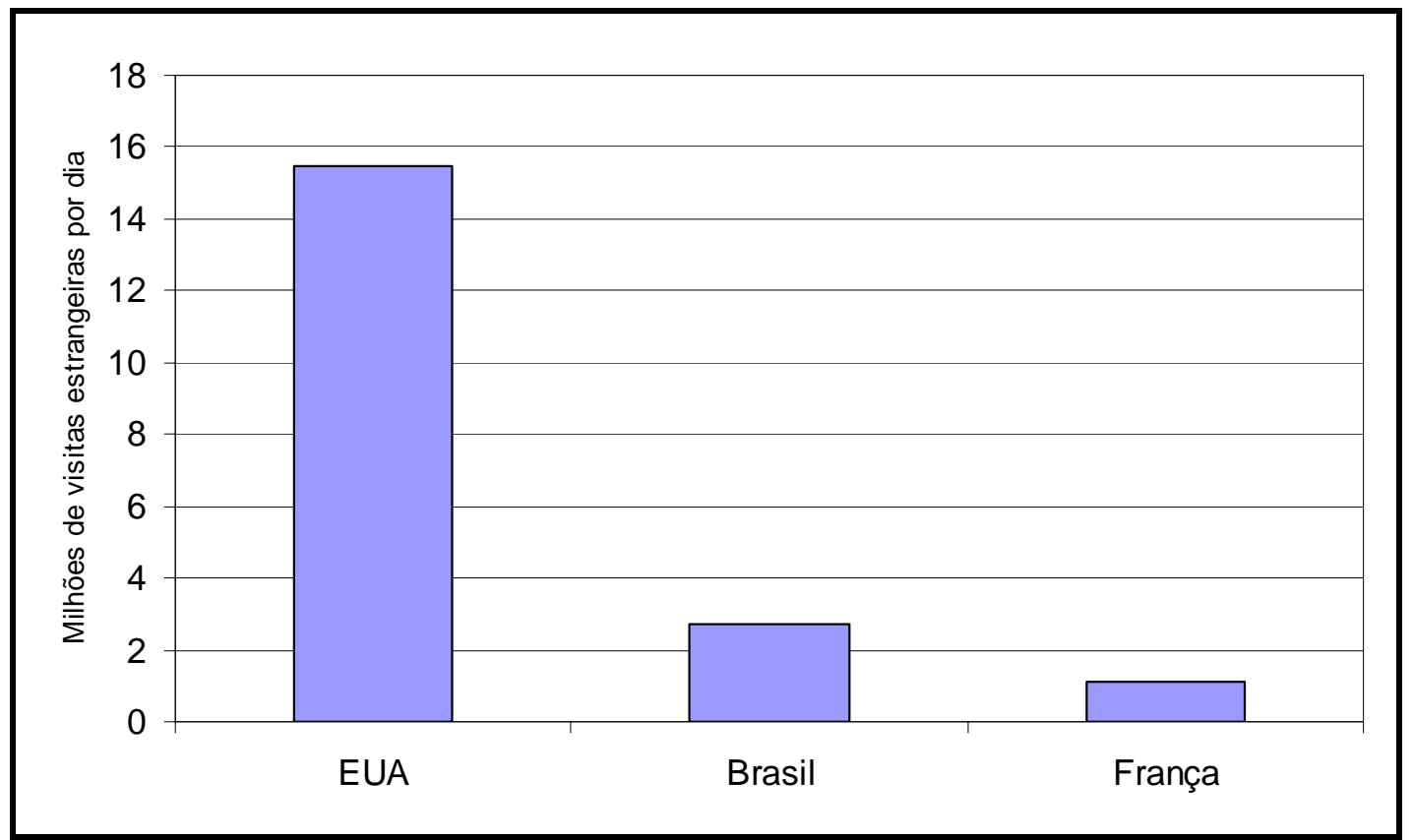

Gráfico 4 - Total de visitas estrangeiras aos principais sites de notícias dos três países. Fonte: João Reino

No estudo dos fluxos da globalização cultural, os números absolutos são mais importantes que os relativos. A influência cultural é evidenciada no número total de pessoas que preferem ler notícias do site da CNN do que do site do Le Monde. Aquele que tiver o maior público, em números absolutos, terá maior poder de influência e irá gerar mais renda para seus anunciantes. Consequentemente, as decisões tomadas por suas equipes editorias, em particular o editor chefe, terão um impacto muito mais abrangente. 
O cenário é ainda mais favorável aos Estados Unidos, e menos favorável ao Brasil, se analisarmos as visitas aos sites das principais revistas impressas ${ }^{25}$ desses países.

Tabela 3 - Número de visitas e porcentual de visitas locais aos sites das principais revistas impressas dos três países

\begin{tabular}{lll|lrr|lrr}
\hline & EUA & & \multicolumn{3}{c|}{ Brasil } & \multicolumn{3}{c}{ França } \\
\hline Revista & Visitas & Porc. & Revista & Visitas & Porc. & Revista & Visitas & Porc. \\
\hline Time & 2.095 .238 & $62,6 \%$ & Veja & 75.113 & $90,9 \%$ & L’Express & 230.366 & $62 \%$ \\
Forbes & 1.851 .851 & $60,5 \%$ & Época & 52.380 & $91,6 \%$ & Le Point & 188.841 & $62,3 \%$ \\
Newsweek & 859.375 & $71,2 \%$ & Istoé $^{26}$ & 466 & $87,8 \%$ & Le Nouvel & 20.614 & $63 \%$ \\
& & & & & & Observateur & & \\
Total & 4.806 .464 & $63,3 \%$ & Total & 127.959 & $91,2 \%$ & Total & 439.821 & $62,1 \%$ \\
\hline
\end{tabular}

Fonte: Alexa.com e websitelookout.com ${ }^{27}$

Em relação às versões online de revistas impressas, a penetração americana é ainda maior em comparação aos outros países pesquisados. A média de público estrangeiro salta de 23,9\% para 35\% nos sites americanos.

Nos sites franceses, o cenário anterior se repete. Apesar de a média de acesso não-local ser de quase 38\%, grande parte dessas visitas vem de suas ex-colônias. Também se repete o fenômeno no qual alguns dos sites franceses são mais populares nas ex-colônias francófonas do que na própria França. O site da revista Le Point, por exemplo, está mais bem posicionado nas listas de sites mais visitados no Haiti, na Costa de Marfim e nos Camarões do que na própria França. Provavelmente trata-se de um reflexo da carência de informação nestes países, a maioria deles são Estados carentes e não industrializados. Entretanto, mais uma vez, tal aspecto requer um estudo específico, não abordado no presente trabalho.

Os números absolutos são menores nos sites de revistas, mas a disparidade da penetração americana é maior, especialmente em relação ao Brasil (ver Gráfico 2). As três revistas americanas analisadas recebem visitas não-locais na ordem de 1,7

\footnotetext{
${ }^{25}$ Como "principais revistas impressas" entendem-se as revistas de notícias de maior circulação em seus respectivos países. Não foram consideradas para o estudo revistas de entretenimento, esportes e material adulto.

${ }^{26}$ O site da revista Istoé apresentou disparidade de 12,2 pontos entre as fontes pesquisadas: o Websitelookout calculou 81,7\% de tráfego nacional no site e o Alexa calculou 93,9\%. Entretanto devido ao número extremamente baixo de visitas esta disparidade não alterou em nada o resultado final, independentemente do valor escolhido que, no caso, foi a média aritmética entre os dois valores.

${ }^{27}$ Ver notas de rodapé 18-21.
} 
milhões por dia. As francesas recebem 165 mil visitas por dia e as brasileiras apenas 11 mil.

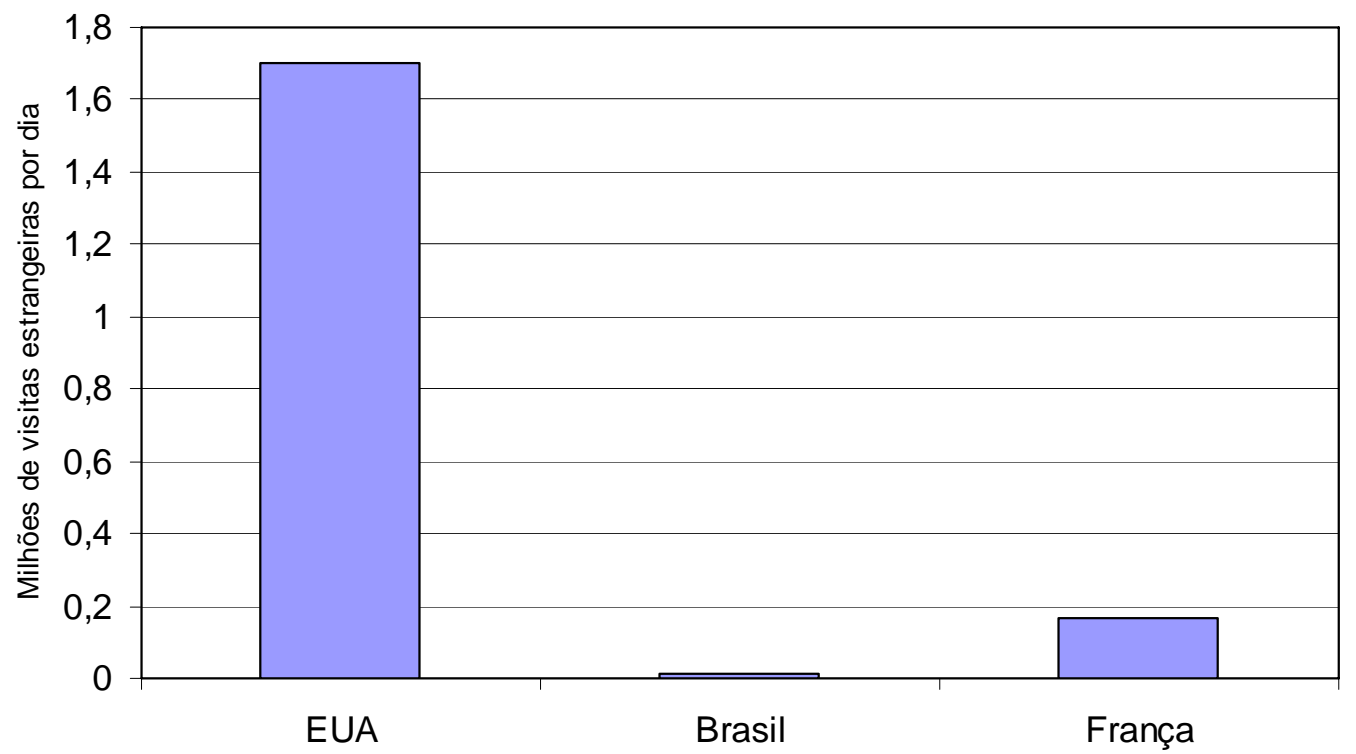

Gráfico 5 - Total de visitas estrangeiras aos sites das principais revistas impressas dos três países. Fonte: João Reino

Além de serem pouco visitadas online, as revistas brasileiras são acessadas quase que exclusivamente por brasileiros. Não seria exagero afirmar que o alcance internacional das principais revistas brasileiras de notícias é nulo ou irrelevante.

Pode-se tentar traçar uma conexão entre influência cultural na Internet e poder econômico ao comparar o PIB dos três países pesquisados: 


\section{Produto Interno Bruto (PIB)}

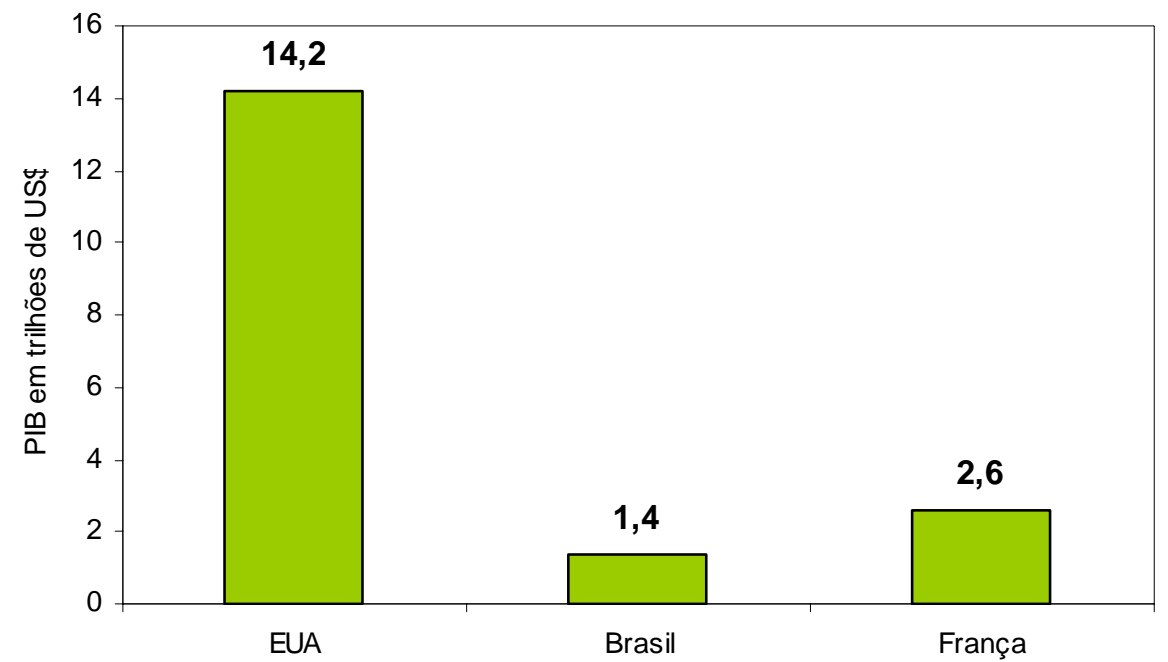

Gráfico 6 - PIB $^{28}$ dos três países. Fonte: CIA (2010). Elaboração do gráfico: João Reino.

O gráfico é proporcionalmente parecido com os anteriores no que tange a posição privilegiada dos Estados Unidos. Entretanto, poder econômico talvez não seja o suficiente para justificar a influência. Se acrescentarmos à análise os dados da China, apenas por questões comparativas, a relação entre poder econômico e influencia cultural não se evidencia:

${ }^{28}$ GDP (official exchange rate) 


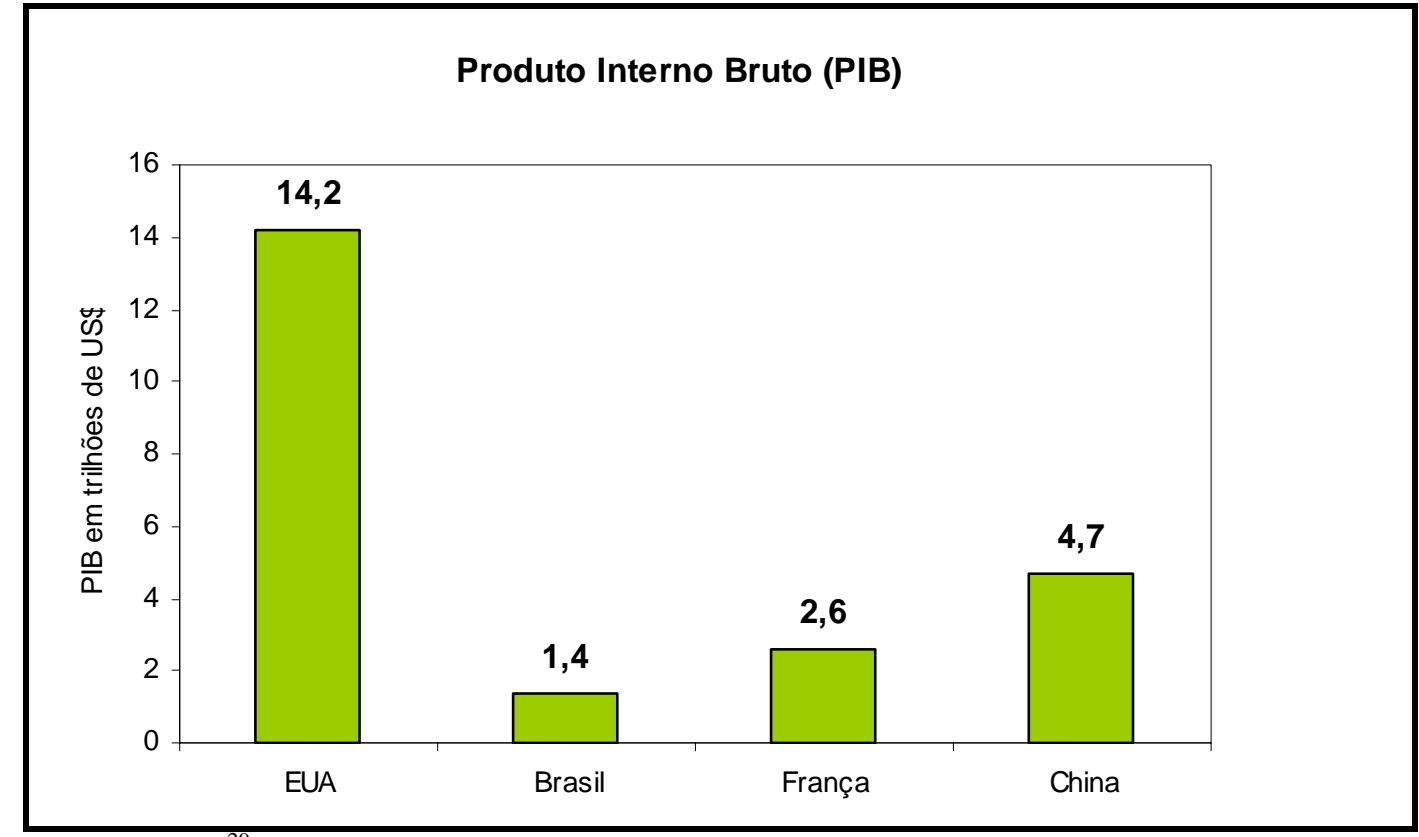

Gráfico 7 - PIB ${ }^{29}$ dos três países mais a China. Fonte: CIA (2010).

Elaboração do gráfico: João Reino

O PIB da China é aproximadamente um terço do PIB americano. Com base no seu poder econômico, a penetração cultural chinesa na Internet deveria ser superior à francesa e à brasileira.

No entanto, uma consulta aos sites de análise de tráfego ${ }^{30}$ nos prova o contrário: os três sites chineses mais populares são visitados exclusivamente por chineses. O total do percentual de visitas chinesas aos três sites é de aproximadamente 97\%. Dos 3\% restantes, a maioria vem dos Estados Unidos, provavelmente da diáspora chinesa que lá reside.

\footnotetext{
${ }^{29}$ Ver nota de rodapé 25

${ }^{30}$ Alexa.com e Websitelookout.com.
} 
Nova observação foi feita, desta vez incluindo o IDH dos quatro países:

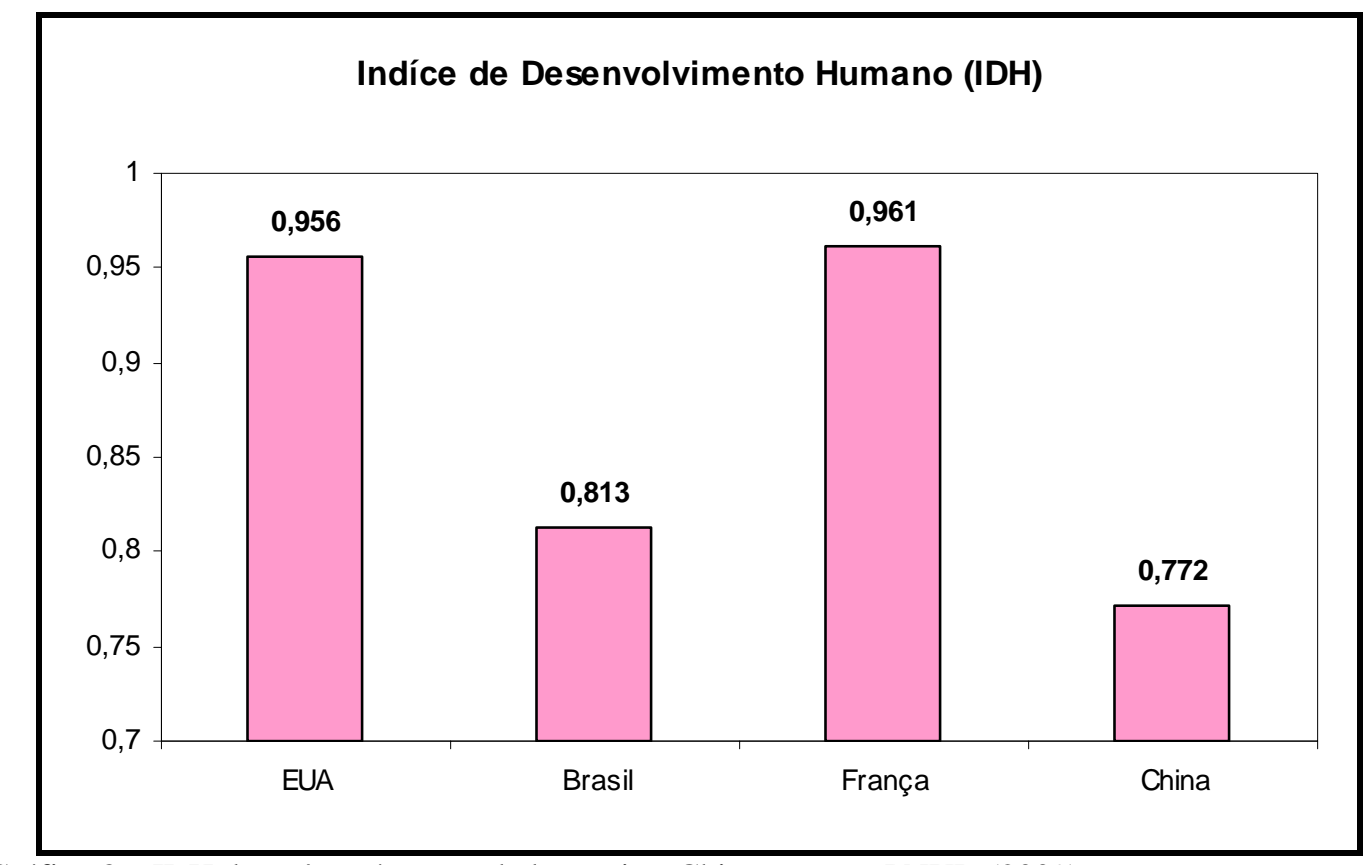

Gráfico 8 - IDH dos três países estudados mais a China. Fonte: PNUD (2009).

Elaboração do gráfico: João Reino

Verifica-se que o IDH dos Estados Unidos (13 ${ }^{a}$ posição) também é alto. Não mais alto que o da França ( $8^{a}$ posição), mas relativamente bem mais alto que o do Brasil ( $75^{\mathrm{a}}$ posição) e o da China ( $92^{\mathrm{a}}$ posição).

É provável que poder econômico aliado a desenvolvimento humano, que por sua vez é o resultado da qualidade de vida proporcionada pelo mesmo poder econômico, favoreça o desenvolvimento cultural e a aceitação de uma cultura por outras, devido ao alto grau de desenvolvimento da primeira e apelo às demais.

Em outras palavras, um Estado próspero - e com liberdade de expressão -, que repassa os benefícios da prosperidade à sua população, proporcionando qualidade de vida a seus cidadãos, recebe em troca desses mesmos cidadãos o fruto de sua criatividade e bem-estar: uma cultura desenvolvida e instigante que atrai a atenção de outras sociedades. 
Certamente parte do processo de desenvolvimento e expansão cultural ocorre de forma natural e parte ocorre devido a interesses corporativos, como já foi exposto no capítulo anterior.

Existe uma indústria da cultura altamente lucrativa por trás da propagação cultural americana, que se beneficia da aceitação mundial de seus produtos. Esta indústria faz parte da infraestrutura da produção, transmissão e recepção cultural de Held (1999), a qual é extremamente desenvolvida nos Estados Unidos, especialmente no que tange a distribuição de seus produtos.

A Internet é apenas mais um meio de distribuição utilizado pela indústria cultural, incluindo a imprensa, para distribuição de seus produtos - filmes, notícias, programas de TV, moda, etc. - e para a maximização dos lucros.

Os meios de produção e transmissão cultural americanos, organizados e bem desenvolvidos, são onde se concentra o poder da globalização cultural, e a Internet até agora não foi capaz de deslocar esse centro emanador de opiniões e idéias e receptor de tráfego.

As notícias, um produto aparentemente neutro e despido de valores, quando transmitidas e recebidas transportam conteúdo cultural da fonte, nem sempre alinhado aos interesses do receptor ( MOWLANA, 1990, p. 225).

O poder da mídia americana é tamanho que, em janeiro de 2006, um erro na tradução simultânea de um discurso do presidente do Irã, Mahmoud Ahmadinejad, transmitido pela CNN, causou um incidente diplomático (CNN, 2006).

No discurso, o presidente do Irã declarou que todo país “tem o direito de usar energia nuclear”. A palavra "energia” foi traduzido como "armas” pelo intérprete contratado pela CNN. A tradução errada foi retransmitida mais tarde no mesmo dia.

Assim que o erro foi identificado pelas autoridades iranianas o chefe de gabinete do presidente Ahmadinejad emitiu nota ao Ministro da Cultura iraniano que, em declaração, acusou a CNN de antiética, afirmou que esse tipo de incidente já 
havia acontecido antes, e baniu repórteres da rede de notícias de entrarem em território iraniano por tempo indeterminado.

Tanto a CNN quanto a agência de tradução contratada tiveram que se desculpar pelo incidente. Mais tarde, o Irã voltou atrás em sua decisão e suspendeu a proibição.

Tal reação, vinda do topo do governo iraniano, evidencia o poder da CNN. Provavelmente nenhum site de notícias brasileiro seria capaz de causar o mesmo impacto. Não que seja o interesse de jornalistas brasileiros cometerem o mesmo erro, mas trata-se da questão do poder nas mãos dos editores dos mais poderosos sites divulgadores de conteúdo do mundo.

O poder de divulgação cultural pela Internet está sob o controle de poucas pessoas. Mesmo com a democratização da publicação de conteúdo em diversos sites, a força do conteúdo "alternativo”, oriundo de canais outros que os grandes propagadores de material, ainda é pulverizada e irrelevante no contexto da globalização cultural.

Não obstante, existem algumas tentativas dos grandes propagadores de material em legitimar seu conteúdo empoderando o usuário comum. Um exemplo disto é o programa i-Report, do site da CNN.

O i-Report é um canal de notícias no portal da CNN onde o usuário pode enviar seus próprios vídeos, com reportagens gravadas e escritas por ele mesmo. Entretanto seria ingênuo acreditar que tudo é publicado. Os artigos encaminhados pelos usuários são submetidos ao crivo do editor chefe e sua equipe, e certamente nada que vá contra os interesses e a estratégia de longo prazo do grupo CNN é publicado no site. O usuário apenas contribui, gratuitamente, para o fortalecimento da rede, desta vez com o poder de legitimidade que só o cidadão comum pode agregar. 


\subsection{IMPERIALISMO OU SICRONIZAÇÃO CULTURAL?}

A presença americana na produção e distribuição de conteúdo na Internet corrobora com a idéia de que os Estados Unidos, através do seu setor privado de produção de mídia, continua exercendo seu poder de influência cultural neste novo meio de comunicação.

A influência cultural americana também é comumente rotulada de “imperialismo cultural”. No entanto, Hamelink (apud MOWLANA, 1990, p. 233) chegou ao termo "sincronização cultural". Ele aponta que o imperialismo cultural é apenas uma forma pela qual a sincronização cultural pode ocorrer.

Não obstante, segundo o próprio Hamelink (apud MOWLANA, 1990, p. 233, tradução nossa), a sincronização cultural também é danosa aos Estados receptores, apesar de nem sempre assumir a forma de imperialismo. Ele coloca:

O processo de sincronização cultural implica na comunicação persuasiva de um desenvolvimento cultural particular do país metropolitano aos países receptores. Todo o processo local de inventividade social e criatividade cultural é arremessado em confusão ou destruído definitivamente.

Aparentemente, o processo tende a destruir as forças diversificadoras. Hamelink (apud MOWLANA, 1990, p. 233, tradução nossa) vai mais longe e fala de uma escolha consciente que os Estados mais fracos devem fazer contra a:

[...] oferta ilusória de integração em uma ordem internacional a qual parece responder a todos os interesses dos países em desenvolvimento, mas que na verdade representa quase que exclusivamente os interesses dos poderosos.

Nesse sentido, a Internet abre-se como um canal de influência cultural que pode ser utilizado por todos, mas parece ter sido apropriada pelos Estados poderosos, em particular pelo mais poderoso de todos, os EUA. 
No entanto, a sincronização cultural não é absoluta. A diversidade não desapareceu e a Internet, apesar de consolidada, ainda não se estruturou definitivamente como meio de comunicação.

O poder do cidadão comum na rede, por exemplo, não pode mais ser considerado como uma variável constante em todo esse cálculo. Apesar de difícil identificação e quantificação, “o nível micro dos indivíduos precisa ser integrado na análise porque as estruturas do nível macro parecem cada vez mais vulneráveis a mudanças na capacitação e na orientação do público que abrangem” (ROSENEAU, 2000, p. 365)

A possibilidade de a Internet ser apropriada e utilizada pelo indivíduo como ferramenta propagadora da diversidade cultural e de que os impactos gerados pelo cidadão comum vão além do nível micro e alcancem as esferas do nível macro do sistema internacional não pode ser totalmente descartada. Os pesquisadores interessados devem ficar atentos a este novo campo de estudos que se desdobra. 


\section{CONCLUSÕES}

A globalização cultural é um dos aspectos mais visíveis da contemporaneidade como um todo. Apesar de os povos já influenciarem uns aos outros há milênios, em particular durante a expansão dos grandes impérios e das grandes religiões, a velocidade e a intensidade com que informação circula nos dias de hoje é algo inédito na história.

Essa intensidade de troca é o resultado de, entre outras coisas, um profundo desenvolvimento nos meios de comunicação ocorrido nos últimos dois séculos. $\mathrm{O}$ mais recente destes avanços foi o advento da Internet no final do século XX.

A Internet se tornou palco da globalização cultural e as forças que operavam nos meios tradicionais de comunicação passaram a atuar também na rede internacional de computadores.

Apesar das grandes expectativas em torno da Internet como agente diversificador da cultura, a direção dos grandes fluxos de informação permanece a mesma, duas décadas após a abertura da World Wide Web.

O controle do conteúdo com maior visibilidade na Internet permanece nas mãos de grandes corporações geradoras de conteúdo.

A maioria dessas empresas é americana e consolida a posição dos Estados Unidos como divulgador predominante de conteúdo.

A influência cultural americana na Internet não é resultado do acaso. O poder de influência cultural americano é presente em outros meios e pode ser explicado de diversas formas.

A explicação presente neste estudo identifica a influência cultural americana como o resultado de poder econômico e bem-estar social aliados à ambição histórica, tão antiga quanto a formação dos Estados Unidos, de expansão e exportação de valores e cultura. 
A globalização cultural que ocorre na Internet é a propagação de conteúdo cultural imbuído de valores ocidentais, mais especificamente, americanos. Trata-se da disseminação de valores capitalistas liberais.

Apesar da produção de conteúdo se concentrar nas mãos de poucas corporações e países, a distribuição é ampla e seu alcance internacional.

Trata-se de uma força de influência cultural homogeneizadora mantida e apoiada por uma infraestrutura de produção e distribuição de artefatos culturais bem desenvolvida, próspera e motivada por interesses corporativos.

O real poder de influência cultural encontra-se, de fato, sob o senhorio daqueles que controlam a informação publicada: os editores-chefes dos principais sites divulgadores de conteúdo e seus anunciantes.

No entanto, faz-se importante notar que a força de homogeneização cultural americana convive com forças diversificadoras. O “rolo compressor” americano não eliminou por completo a influência de outras culturas na Internet.

Com efeito, o ambiente democrático e barato da Internet para a publicação de conteúdo faz com que a predominância da influência americana não necessariamente expulse influências alternativas, ao contrário do que ocorre nos meios tradicionais. 


\section{REFERÊNCIAS}

ARRAES, Virgílio, A Potência em Crise: Os Estados Unidos no Início do Século XXI. Brasília: Editora Verdana, 2009.

BRAUER, Kinley. Manifest Destiny Revisited. Diplomatic History, Vol. 23, nº 2, p. 379-384, 1999. Disponível em:

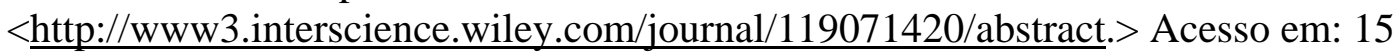
mar. 2010.

CARR, Edward H. Vinte Anos de Crise: 1919-1939. Uma Introdução ao Estudo das Relações Internacionais. 2 ed. Brasília: Editora Universidade de Brasília, 2001.

CIA, Central Intelligence Agency. Origins of the Congress for Cultural Freedom, 1949-50, disponível em <https://www.cia.gov/library/center-for-the-study-ofintelligence/csi-publications/csi-studies/studies/95unclass/Warner.html>, acesso em 09 março 2010.

The World Factbook, 2010. Disponível em:

$<$ https://www.cia.gov/library/publications/the-world-factbook $>$. Acesso em 05 mar. de 2010.

CNN International. Reports: Iranian president asks end to CNN ban. 14 jan. 2006. Disponível em:

< http://edition.cnn.com/2006/WORLD/meast/01/16/iran.cnn/index.html $>$. Acesso em 09 mar. 2010.

COLES, Roberta L. Manifest Destiny Adapted for 1990s’ War Discourse: Mission and Destiny Intertwined. Sociology of Religion, Vol 63, n 4, p. 403-426, 2002. Disponível em: <http://www.jstor.org/stable/3712300> . Acesso em: 19 mar. 2010.

CZEMPIEL, Ernst-Otto. Governança e Democratização. In: CZEMPIEL, E.; ROSENAU, J. N. (Org.). Governança sem Governo: Ordem e transformação na política mundial. Brasília: Editora Universidade de Brasília, 2000. Cap. 9.

ELIOT, Thomas. S. Notes towards the Definition of Culture. Nova Iorque: Harcourt, Brace and Company, 1949.

FRIEDEN, Jeffry A. Capitalismo Global: História Econômica e Política do Século XX. Rio de Janeiro: Jorge Zahar Ed., 2008.

FRIEDMAN, Thomas L. O Mundo é Plano: o Mundo Globalizado no Século XXI. 3. ed. Rio de Janeiro: Objetiva, 2009. 1999.

O Lexus e a Oliveira: Entendendo a Globalização. Rio de Janeiro: Objetiva, 
GALTUNG, Johan. U.S. Foreign Policy as Manifest Theology. In: JONGSUK, Chay (Org.). Culture and International Relations. Rio de Janeiro: Jorge Zahar Ed., 1990. Cap. 9.

GUIMARÃES, Samuel P., Quinhentos Anos de Periferia. 5 ed. Rio de Janeiro: Contraponto, 2007.

HEDETOFT, Ulf. The Nation-state Meets the World: National Identities in the Context of Transnationality and Cultural Globalization. European Journal of Social Theory, 2, p. 71-94, 1999. Disponível em:

<http://est.sagepub.com/cgi/content/abstract/2/1/71>. Acesso em: 15 mar. 2010.

HEDGES, Chris. The Information Super-Sewer. 2010. Disponível em http://www.truthdig.com/report/item/the_information_super-sewer_20100214/ Acessado em 2 jan 2010.

HELD, David et. al. Global Transformations: Politics, Economics and Culture. Califórnia: Stanford University Press, 1999.

HELD, D.; McGrew, A (Org.). The Global Transformations Reader: An Introduction to the Globalization Debate. 2. ed. Cambridge: Polity Press, 2003

HERMAN, E.S.; CHOMSKY, N. A Manipulação do Público: Política e poder econômico no uso da mídia. São Paulo: Futura, 2003.

JACKSON, R.; SORENSEN, G. Introdução às Relações Internacionais. Rio de Janeiro: Jorge Zahar Ed., 2007.

JAY, Paul. Beyond Discipline? Globalization and the Future of English. PMLA, Vol. 116, No. 1, Special Topic: Globalizing Literary Studies, p. 32- 47, 2001.

Disponível em: <http://www.jstor.org/stable/463639> Acesso em 19 mar. 2010.

JONGSUK, Chay (Org.). Culture and International Relations. Nova Iorque: Praeger Publishers, 1990. p. xi-xii.

JORGENSEN, Estelle R. Music and International Relations. In: JONGSUK, Chay (Org.). Culture and International Relations. Rio de Janeiro: Jorge Zahar Ed., 1990. Cap. 5.

LANIER, Jaron. Digital Maoism: The Hazards of the New Online Collectivism, 2006. Disponível em http://www.edge.org/3rd_culture/lanier06/lanier06_index.html Acessado em 5 jan 2010.

LEINER, Barry et. al. A Brief History of the Internet. Disponível em <http://www.isoc.org/internet/history/brief.shtml. $>$ Acesso em 10 mar. 2010. 
MARSHALL, Leandro. A Estética da Mercadoria Jornalística. Disponível em $<$ http://www.bocc.uff.br/pag/marshall-leandro-estetica-mercadoria-jornalistica.pdf $>$. Acesso em 20 março 2010.

PNUD, Programa das Nações Unidas para o Desenvolvimento. Relatório para o Desenvolvimento Humano, 2007. Disponível em

$<$ http://hdr.undp.org/en/media/HDR_2009_EN_Complete.pdf $>$. Acesso em 09 mar. 2010.

PRADO, Luiz C. D. Globalização: Notas sobre um Conceito Controverso. In: LACERDA, A. C. (Org.). Crise e Oportunidade: o Brasil e o Cenário Internacional. Lazuli Editora, 2006.

ROSENAU, James N. A cidadania em uma ordem mundial em mutação. In: CZEMPIEL, E.; ROSENAU, J. N. (Org.). Governança sem Governo: Ordem e transformação na política mundial. Brasília: Editora Universidade de Brasília, 2000. Cap. 10.

SARAIVA, J. F. S. (Org.). História das Relações Internacionais

Contemporâneas: da Sociedade Internacional do Século XIX à Era da Globalização. 2. ed. São Paulo: Editora Saraiva, 2008.

SCHUMPETER, Joseph A. Capitalismo, Socialismo e Democracia. Rio de Janeiro: Editora Fundo de Cultura, 1961.

WALKER, R. B. J. The Concept of Culture in the Theory of International Relations. In: JONGSUK, Chay (Org.). Culture and International Relations. Rio de Janeiro: Jorge Zahar Ed., 1990. Cap. 1. 


\section{APÊNDICE A}

Este apêndice reúne as versões originais das traduções de trechos em idioma estrangeiro citados no trabalho.

Página 13 (Walker, 1990, p. 12) "to develop a conscious amnesia toward those assumptions and contradictions through which the term has been shaped historically.”

Página 13 (Williams apud Walker,1990, p. 4) “one of the two or three most complicated words in the English language.”

Página 14 (Walker, 1990, p. 4) "the seemingly inevitable tendency for cooperation to collapse in the face of interstate competition and rivalry."

Página 15 (Walker, 1999, p. 10) "the amoral realm of realpolitik”; "hindrances to the special responsibilities of statesmen struggling to maintain order in a realm tragically devoid of ethical standards."

Página 15 (Eliot, 1949, p. 25) "we become more and more aware of the extent to which the baffling problem of 'culture' underlies the problems of the relation of every part of the world to every other.”

Página 15 (Eliot, 1949, p. 27) "We may [...] whether what we call the culture, and what we call the religion, of a people are not different aspects of the same thing: the culture being [...] the incarnation (so to speak) of the religion of a people."

Página 16 (Eliot, 1949, p. 26) “Culture may even be described simply as that which makes life worth living."

Página 17 (Held, 1999, p. 329) "culture as a lived and creative experience for individuals as well as a body of artefacts, texts and objects."; “it embraces the specialized and professionalized discourses of the arts, the commodified output of the culture industries, the spontaneous and unorganized cultural expressions of everyday life, and [...] the complex interactions between all of these.”

Página 20 (Eliot, 1949, p. 62) “a world culture which was simply a uniform culture would be no culture at all. We should have a humanity de-humanised.”

Página 21 (Held, 1999, p. 328) "the existence of transregional, transcivilizational and transcontinental cultural flows and institutions - cultural globalization - has deep historical roots.”

Página 21 (Eliot, 1949, p.26) “The development of culture and the development of religion [...] cannot be clearly isolated from each other.”

Página 22 (Held, 1999, p. 328) “from around the late eighteenth century onwards, the centrality of these older forms of cultural globalization was displaced, on the one had, by the emergence of nation-states, national cultures and national cultural institutions, and, on the other, by the development and diffusion of new secular Western ideologies [...]: pre-eminently those of liberalism, socialism and science."

Página 22 (Hedetoft, 1999, p.72) "political and cultural organizing principle of massindustrial modernity"

Página 22-23 (Held, 1999, p. 328) “despite the cosmopolitan and internationalist claims of aspects of these ideologies and modes of thinking, and the development of new Technologies of cultural transmission from the latter half of the nineteenth century [...], the balance of effective culture power for most of the last two hundred years has lain with nation-states and national cultures.”

Página 23 (Held, 1999, p. 328) "in the contemporary era a series of technological and institutional transformations have once again altered that balance. New technologies of telecommunications and the emergence of international media corporations, among other factors, have 
generated global cultural flows whose stretch, intensity, diversity and rapid diffusion exceed that of earlier eras.”

Página 23 (Held, 1999, p. 330) "cultural practices can be and are actively imposed in places distant from their original site of production.”; "The movement and adoption of cultural practices can occur by active importation and reproduction."

Página 24 (Hedetoft, 1999, p. 79) "transnational, intercultural and identity-shaping forces.”

Página 27 (Hook apud CIA, 2007) "Give me a hundred million dollars and a thousand dedicated people, and I will guarantee to generate such a wave of democratic unrest among the masses--yes, even among the soldiers- of Stalin's own empire, that all his problems for a long period of time to come will be internal. I can find the people."

Página 28 (Mowlana, 1990, p. 224) "the battlefield of international politics has shifted from the geographical and the physical, to the ideological, communication, and cultural levels."

Página 35 (Hedges, 2010) "one more tool hijacked by corporate interests to accelerate our cultural, political and economic decline.”

Página 36 (Lanier apud Hedges, 2010) "copied, mashed up, anonymized, analyzed, and turned into bricks in someone else’s fortress to support an advertising scheme.

Página 37 (Lanier apud Hedges, 2010) "Digital collectivism [...] is destroying the dwindling vestiges of authentic creativity and innovation."

Página 37 (Hedges, 2010) "utopian promoters of the Internet.” control it.”

Página 38 (Hedges, 2010) "Technology is morally neutral. It serves the interests of those who

Página 49 (Hamelink apud Mowlana, 1990, p. 233) "the process of cultural synchronization implies that a particular type of cultural development in the metropolitan country is persuasively communicated to the receiving countries. The whole process of local social inventiveness and cultural creativity is thrown into confusion or is definitely destroyed"; “[...] delusory offer o integration in an international order which appears to respond to all the interests of the developing countries, but which in fact represents almost exclusively the interests of the powerful." 